\title{
DOE/PC/95101--75
}

Report Title:

\section{TOXIC SUBSTANCES FROM COAL COMBUSTION A COMPREHENSIVE ASSESSMENT}

Report Type:

Principal Author(s): L.E. Bool III and C.L. Senior (1)

F. Huggins, G.P. Huffman and N. Shah (2)

J.O.L. Wendt and T.W. Peterson (3)

A.F. Sarofim, I. Olmez, and T. Zeng (4)

S. Crowley and R. Finkelman (5)

Report Issue Date: 01/31/1997

DOE Award No.: DE- AC22

-95PC95101

Submitting

Organization(s)

Name \& Address

Physical Sciences Inc.

20 New England Business Center

Andover, MA 01810-1077

University of Kentucky

Lexington, KY 40506-0059

(2)

University of Arizona

Tucson, AZ 85721

PROCESSED FROM BEST AVAILABLE COPY

U.S. Geological Survey

Reston, VA 22092 
This report was prepared as an account of work sponsored by an agency of the United States Government. Neither the United States Government nor any agency thereof, nor any of their employees, makes any warranty, express or implied, or assumes any legal liability or responsibility for the accuracy, completeness, or usefulness of any information, apparatus, product, or process disclosed, or represents that its use would not infringe on privately owned rights. Reference herein to any specific commercial product, process, or service by trade name, trademark, manufacturer, or otherwise does not necessarily constitute or imply its endorsement, recommendation, or favoring by the United States Government or any agent thereof. The views and opinions of authors expressed herein do not necessarily state or reflect those of the United States Government or any agency thereof. 


\section{DISCLAMIER}

Portions of this document may be illegible in electronic image products. Images are produced from the best available original document. 


\begin{abstract}
The Clean Air Act Amendments of 1990 identify a number of hazardous air pollutants (HAPs) as candidates for regulation. Should regulations be imposed on HAP emissions from coal-fired power plants, a sound understanding of the fundamental principles controlling the formation and partitioning of toxic species during coal combustion will be needed. With support from the Federal Energy Technology Center (FETC), the Electric Power Research Institute, and VTT (Finland), Physical Sciences Inc. (PSI) has teamed with researchers from USGS, MIT, the University of Arizona (UA), the University of Kentucky (UKy), the University of Connecticut, and Princeton University to develop a broadly applicable emissions model useful to regulators and utility planners. The new Toxics Partitioning Engineering Model (ToPEM) will be applicable to all combustion conditions including new fuels and coal blends, low- $\mathrm{NO}_{\mathrm{x}}$ combustion systems, and new power generation plants. Development of ToPEM will be based on PSI's existing Engineering Model for Ash Formation (EMAF). During the past quarter the final program coal, from the Wyodak seam in the Powder River Basin, was acquired and distributed. Extensive coal characterization and laboratory work is underway to develop and test new sub-models. Coal characterization in the past quarter included direct identification of the modes of occurrence of various trace inorganic species in coal and ash using unique analytical techniques such as XAFS analysis and selective leaching. Combustion testing of the bituminous coals continued and additional data were obtained on trace element vaporization in the combustion zone. Studies of post-combustion trace elemient transformations, such as mercury speciation in the flue gas, were also begun in the last quarter.
\end{abstract}




\section{TABLE OF CONTENTS}

Section $\quad$ Page

1. EXECUTIVE SUMMARY $\ldots \ldots \ldots \ldots \ldots \ldots \ldots \ldots \ldots \ldots \ldots \ldots \ldots \ldots \ldots$

2. INTRODUCTION AND PROGRAM OVERVIEW $\ldots \ldots \ldots \ldots \ldots \ldots \ldots \ldots \ldots$

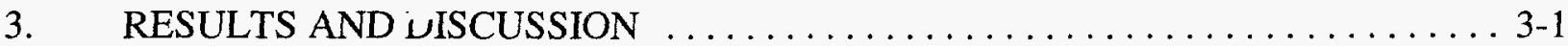

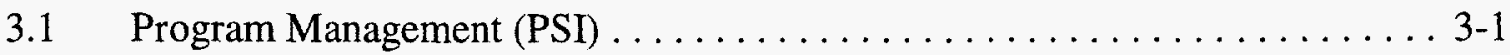

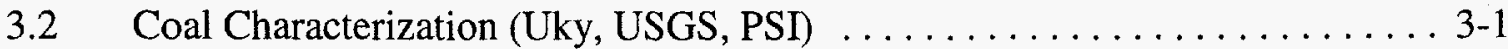

3.3 Combustion Zone Transformations (PSI, MIT, Uk.y) . . . . . . . . . . . . . . 3-9

3.4 Post-Combustion Transformations (UA, PSI, Uky) ........... 3-21

4. CONCLUSIONS $\ldots \ldots \ldots \ldots \ldots \ldots \ldots \ldots \ldots \ldots \ldots \ldots \ldots \ldots \ldots \ldots \ldots$

5. REFERENCES $\ldots \ldots \ldots \ldots \ldots \ldots \ldots \ldots \ldots \ldots \ldots \ldots \ldots \ldots \ldots \ldots$

APPENDIX A Preliminary Raw Leaching Data -- Derived from

Analysis of Leachate Solutions $\ldots \ldots \ldots \ldots \ldots \ldots \ldots \ldots \ldots \ldots \ldots \ldots$ A-1 


\section{LIST OF GRAPHICAL MATERIALS}

Figure No.

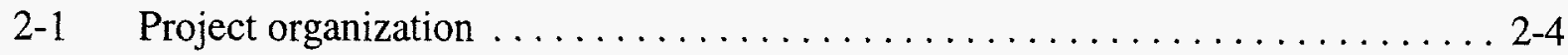

3-1 Se XANES of raw Illinois No. 9 coal and float/sink fractions $\ldots \ldots \ldots \ldots .7$

3-2 Se XANES of raw Elkhorn/Hazard coal and float/sink fractions $\ldots \ldots \ldots \ldots$. . . .

3-3 Zn XANES of raw Illinois No. 9 coal and float $/$ sink fractions $\ldots \ldots \ldots \ldots . . . .3-9$

3-4 Zn XANES of raw Elkhorn/Hazard coal and float/sink fractions $\ldots \ldots \ldots \ldots 3-10$

3-5 Mossbauer spectrum of Illinois No. 6 "weathered" for 60 days at $50^{\circ} \mathrm{C} \ldots \ldots \ldots 3-11$

3-6 Cumulative ash particle size distributions for three bituminous coals $\ldots \ldots \ldots$ 3-12

3-7 Cumulative submicron ash particle size distributions for three

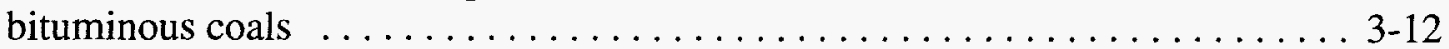

3-8 Cumulative ash particle size distributions for Elkhorn/Hazard at

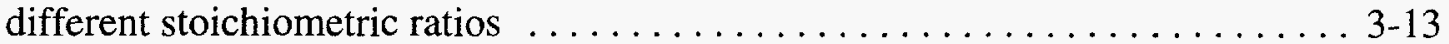

3-9 Cumulative submicron ash particle size distributions for Elkhorn/Hazard at different stoichiometric ratios

3-10 Cumulative ash particle size distributions for the Pittsburgh coal at different stoichiometric ratios

3-11 Cumulative submicron ash particle size distributions for the Pittsburgh coal at different stoichiometric ratios . . . . . . . . . . . . . . . . . . . . 3-14

3-12 Fractional vaporization for several elements in the Elkhorn/Hazard coal at different stoichiometric ratios

3-13 Fractional vaporization for several elements in the Elkhorn/Hazard coal

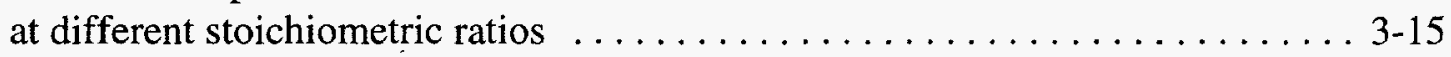

3-14 Effect of As concentration in coal on the total As collected in submicron ash . . 3-17

3-15 Effect of $\mathrm{Zn}$ concentration in coal on the total $\mathrm{Zn}$ collected in submicron ash . . 3-18

3-16 Effect of Fe concentration in coal on the total Fe collected in submicron ash ... 3-19

3-17 Effect of $\mathrm{Cr}$ concentration in coal on the total $\mathrm{Cr}$ collected in submicron ash . . 3-20

3-18 Effect of Na concentration in coal on the total Na collected in submicron ash . . 3-21

3-19 Sulfur XANES spectra of chars from three program coals $\ldots \ldots \ldots \ldots \ldots .22$

3-20 Schematic of reactor for mercury capture experiments $\ldots \ldots \ldots \ldots \ldots \ldots$ 3-23

3-21 Hg XANES spectra and related data for four chars supplied by UNDEERC . . . 3-25

3-22 Radial structure functions for $\mathrm{Hg}$ in three activated carbons . . . . . . . . . . . 3-26

3-23 Schematic of the Ontario-Hydro apparatus $\ldots \ldots \ldots \ldots \ldots \ldots \ldots \ldots \ldots \ldots \ldots \ldots \ldots .27$ 


\section{LIST OF TABLES}

Table No. Page

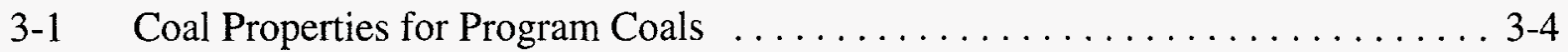

3-2 Mean Percentages of Arsenic Leached (Error $\pm 25 \%) \ldots \ldots \ldots \ldots \ldots$. $3-6$

3-3 Comparisons of As and Se Step-Heights and wt \% Pyritic Sulfur for

Elkhorn/Hazard and Illinois \#6 Coals $\ldots \ldots \ldots \ldots \ldots \ldots \ldots \ldots \ldots \ldots . \ldots \ldots$

3-4 Hg Distribution in Ash Produced by Coal Combustion $\mathrm{T}_{\text {furnace }}=1700 \mathrm{~K}$,

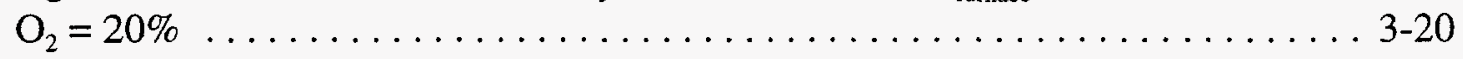

3-5 \% $\mathrm{S}$ in Different Forms in Char Samples from Sulfur XANES Spectroscopy . . . 3-22 
SECTION 1

EXECUTIVE SUMMARY

$1-1 / 1-2$ 


\section{EXECUTIVE SUMMARY}

The technical objectives of this project are:

a. To identify the effect of the mode-of-occurrence of toxic elements in coal on the partitioning of these elements among vapor, submicron fume, and fly ash during the combustion of pulverized coal,

b. To identify the mechanisms governing the post-vaporization interaction of toxic elements and major minerals or unburnt char,

c. To determine the effect of combustion environment (i.e., fuel rich or fuel lean) on the partitioning of trace elements between vapor, submicron fume, and fly ash during the combustion of pulverized coal,

d. To model the partitioning of toxic elements between various chemical species in the vapor phase and between the vapor phase and complex aluminosilicate melts,

e. To develop a frame work for incorporating the results of the program into the Engineering Model for Ash Formation (EMAF).

A description of the work plan for accomplishing these objectives is presented in Section 2.1 of this report.

The work discussed in this report highlights the accomplishments of the fifth quarter of this program. These accomplishments include the acquisition and distribution of the final Phase I program coal. In the ongoing coal characterization efforts XAFS and selective leaching were used to determine the forms of occurrence of various trace elements. Combustion experiments were performed at two different scales to explore vaporization of trace elements in the combustion zone. Combustion experiments were also begun on several scales to evaluate trace element transformations in the post-combustion zone.

Specifically, the final program coal, from the Wyodak seam of the Powder River Basin, was acquired from $\mathrm{ABB}$. This coal is currently being used in a DoE funded program to evaluate ESP performance. The coal was then distributed to all team members and stored under argon.

XAFS analysis was utilized to measure the forms of occurrence of zinc and selenium in selected program coals. For example, this technique was used to show that selenium is primarily associated with pyrite in the Pittsburgh coal. In the Elkhorn/Hazard this element is primarily organically associated. Preliminary data were also obtained from the selective leaching procedure performed earlier in the program on the three bituminous coals. These data indicate that a significant portion of the arsenic in the Elkhorn/Hazard coal was not leached by any of the solvents used in the USGS leaching protocol. Comparison of the leaching and XAFS data suggest that the unleached portion may be due to extremely fine pyrite inclusions. In the other 
bituminous coals the leaching data suggest that the arsenic was primarily associated with the pyrite -- corroborating the earlier XAFS findings for these coals.

Combustion experiments in the past quarter focussed primarily on vaporization of trace elements in the combustion zone. Size and density fractions of all three coals were burned in the MIT droptube furnace and size segregated ash samples were collected. Utility grind samples of the Pittsburgh, Elkhorn/Hazard, and Illinois No. 6 coals were burned under baseline (stoichiometric ratio of 1.2) conditions in the PSI entrained flow reactor (EFR). Data from the MIT experiments were compared with earlier data presented by Quann ${ }^{1}$ and found to follow similar vaporization trends. The PSI data showed that the degree of vaporization was higher for the combustion experiments performed under fuel lean conditions.

Experiments were also begun to explore post-combustion trace element partitioning. These experiments included preliminary combustion experiments on the self-sustained combustor at UA, mercury speciation measurements at PSI, and the development of an experimental apparatus to measure mercury absorption on coal chars. The experiments on the laboratory-scale combustor were performed by a joint team of PSI and UA investigators and served to 'shake-down' the system and prepare the UA investigators for sampling with the Berner Low Pressure Impactor (BLPI). Preliminary mercury speciation measurements in flue gas from combustion of the Illinois No. 6 coal under baseline conditions at PSI were performed using the Ontario-Hydro method. This method was recommended by investigators in the ongoing program to evaluate methods for measuring mercury speciation in flue gas being performed by DoE, the Electric Power Research Institute (EPRI), and the University of North Dakota Energy and Environmental Research Center (UNDEERC). Preliminary data suggest that there is a much lower fraction of oxidized mercury present at temperatures below $750 \mathrm{~K}$ than predicted from equilibrium. To study mercury uptake by residual carbon in combustion systems, chars were produced from the three bituminous coals in the program and characterized by XAFS to determine the forms of sulfur present in the chars. The experimental apparatus to study mercury uptake on chars was designed and fabricated at UA during the last quarter. 
SECTION 2

INTRODUCTION AND PROGRAM OVERVIEW

$2-1 / 2-2$ 



\section{INTRODUCTION AND PROGRAM OVERVIEW}

Before electric utilities can plan or implement emissions minimization strategies for hazardous pollutants, they must have an accurate and site-specific means of predicting emissions in all effluent streams for the broad range of fuels and operating conditions commonly utilized. Development of a broadly applicable emissions model useful to utility planners first requires a sound understanding of the fundamental principles controlling the formation and partitioning of toxic species during coal combustion (specifically in Phase I, As, $\mathrm{Se}, \mathrm{Cr}$, and possibly $\mathrm{Hg}$ ). PSI and its team members will achieve this objective through the development of an "Engineering Model" that accurately predicts the formation and partitioning of toxic species as a result of coal combustion. The "Toxics Partitioning Engineering Model" (ToPEM) will be applicable to all conditions including new fuels or blends, low- $\mathrm{NO}_{\mathrm{x}}$ combustion systems, and new power systems being advanced by DOE in the Combustion 2000 program.

Based on a goal of developing and delivering this ToPEM model, a 5-year research program was proposed. This program is divided into a 2-year Phase I program and a 3-year Phase II program. The objective of the ongoing Phase I program is to develop an experimental and conceptual framework for the behavior of selected trace elements (arsenic, selenium, chromium, and mercury) in combustion systems. This Phase I objective will be achieved by a team of researchers from MIT, UA, UKy, Princeton University, the University of Connecticut, and PSI. Model development and commercialization will be carried out by PSI.

Our general approach to the development of the ToPEM model is to break the process for toxic formation into sub-processes, each of which will be addressed by team members who are experts in the area. Ultimately, this will result in new sub-models which will be added to the existing Engineering Model for Ash Formation (EMAF) to create ToPEM. Figure 2-1 illustrates the relationship between the elements of the Phase I work breakdown structure and the subprocesses. Each of the areas identified in the figure will be addressed in the Phase I program as described below.

\section{Program Overview}

\section{Forms of Occurrence of Trace Elements in Coal}

One of the most important questions to be answered in the program as a whole is whether the form of a particular element in the coal affects its form of emission at the end of the process. The answer to this question will determine the shape of the sub-models that must be developed in this program. Thus, a detailed understanding of the forms of individual trace elements in coal provides a foundation for much of the rest of the program. Key issues that are being addressed in Phase I are the specific mineral associations of individual elements and the relationship between trace metal form and "standard" analyses.

Because of the importance of elemental form (e.g., sulfate versus silicate mineral) on partitioning, it is critical that coals representing a broad range of elemental forms be examined in this program. In Task 2 we selected and acquired a total of four coals for study in this program. 


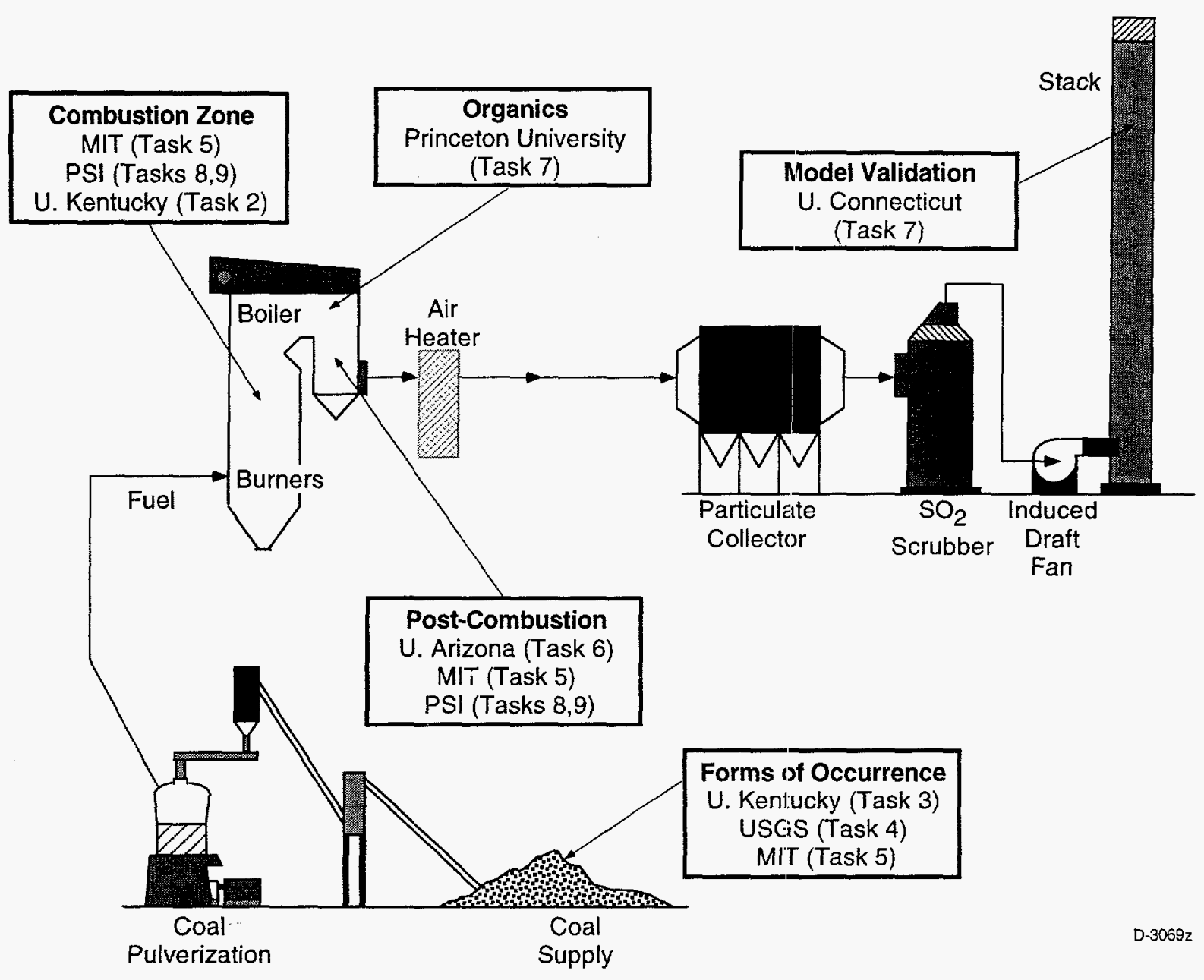

Figure 2-1. Project organization.

The coals chosen (1) represented a broad range of elemental forms of occurrence; (2) represented the major coal ranks and commercial coal seams used for pulverized coal (PCs power generation in the US; and (3) included "future fuels" such as blends and beneficiated coals. Once selected fresh coal samples were acquired and distributed to team members. These samples were subjected to ultimate, proximate, and ASTM ash analysis. Coal samples were analyzed for trace element concentrations by INAA at the MIT Nuclear Reactor Laboratory (Task 5).

Advanced analytical techniques such as Mössbauer spectroscopy and CCSEM are being used by UKy (Task 3 ) to determine the major mineral species present in the program coals and the combustion generated ash. This analysis provides important insight on the minerals present in the coal, how they interact during the combustion process, and how this interaction may affect the partitioning of toxic elements.

Another important issue is the form-of-occurrence of the trace elements in the coal. In this task the mode of occurrence of $\mathrm{As}, \mathrm{Cr}$, and Se is being determined by combining XAFS and the Mössbauer/CCSEM derived data discussed above. Hg will also be evaluated. Other less 
critical trace elements ( $\mathrm{Mn}, \mathrm{Ni}, \mathrm{Zn}, \mathrm{Pb}, \mathrm{U}$, etc.) may also be evaluated, especially if their abundance is unusually high in any of the program coals. In addition, the form-of-occurrence of $\mathrm{Cl}$ and $\mathrm{S}$ in coals and chars will be investigated.

As a complement to the time-intensive XAFS analysis mentioned above, a unique protocol developed by USGS is being used in Task 4 to analyze selected raw coal, and size and density segregated coal, samples for trace element forms of occurrence. This protocol combines low temperature $\left(<200^{\circ} \mathrm{C}\right)$ ashing, chemical analysis, $\mathrm{x}$-ray diffraction, coal segregation via flotation, ammonium acetate and selected acid leaching, electron microbeam measurements, and low and moderate temperature heating tests to determine the forms of elements in coal. Because of the unique combination of existing testing and analytical facilities available at USGS, the work is being conducted at USGS laboratories. In addition, a relatively new technique, synchrotron radiation X-ray fluorescence microscopy (SRXFM), available at the National Synchrotron Light Source, will be tested for application in this area by UKy (Task 3). This technique uses $\mathrm{x}$-ray fluorescence excited by a focussed synchrotron $\mathrm{x}$-ray beam for imaging and compositional analysis. The $\mathrm{x}$-ray yield obtained from a given element is viders of magnitude greater than that possible in an electron microscope or microprobe; hence, its sensitivity to trace element modes is much better, particularly for modes of occurrence involving highly dispersed elements

\section{Combustion Zone Transformations}

The effect of coal type and combustion conditions on the emission of the toxic trace elements is being investigated using the MIT laminar-flow drop tube reactor (Task 5). The fundamental mechanisms of toxic species formation and partitioning will be determined from careful examination of the ash formed under a variety of combustion conditions. Measurements of the partitioning of the trace elements in the four coals as a function of temperature and equivalence ratio are underway. These measurements will provide the baseline data on the fraction vaporized for the different elements to be studied in greater detail in Phase II of the program. Individual size-segregated ash samples (collected with a cascade impactor) are then analyzed by INAA for total composition, Auger and STEM for surface composition, TEM and SEM for particle morphology, and possibly water washing and/or chemical leaching to determine the solubility of selected trace elements in the ash samples. Samples are also be submitted to UKy for chemical species analysis by XAFS and other techniques.

PSI will be performing a detailed experimental study to determine the fundamental behavior of toxic species during combustion, including low $\mathrm{NO}_{\mathrm{x}}$ conditions (Task 8). The work utilizes the PSI EFR that has been used in many previous combustion studies on mineral matter transformations during pc combustion. This reactor is on a scale intermediate between the bench top apparatus to be used by other team members (UA, MIT) and the UA laboratory-scale combustor. Therefore the combustor yields a better understanding of the overall behavior of toxic species while avoiding some of the confounding influences related to self-sustained combustion in the larger furnace. Utility-grind samples of the program coals are combusted under three different stoichiometric ratios, and two temperatures. Size segregated ash samples, and carbon filter samples will be collected. Ash samples collected during the combustion experiments are analyzed by INAA and other techniques at MIT. By performing an elemental 
analysis on the size classified ash samples, we can identify the major mechanisms (e.g., vaporization and condensation) that govern the behavior of specific toxic species during the combustion process -- especially under reducing conditions.

\section{Post-Combustion Transformations}

The goal of this task is an increased understanding of the transformations of selected metals as the flue gases cool following the high temperature combustion zone. Experiments will be performed on two very different scales at UA. In addition, PSI will perform thermodynamic equilibrium calculations and make measurements of submicron aerosol size and composition from the large self-sustained combustor (Tasks 8 and 9).

At the small scale, UA will conduct experiments to explore the fundamental kinetics and mechanisms for metal vaporization and metal vapor-mineral interactions. Metal vapor-mineral interactions will be studied in this task using thermogravimetric analysis (TGA). The primary experimental parameters to be studied are temperature, gas composition (particularly the concentration of the metal species in the gas phase), the composition of the sorbent (char, silica, alumino-silicate, etc.), sorbent particle size and porosity, and exposure time (residence time). The primary properties that will be analyzed are the concentration of toxic trace metals in the particles as functions of time, the final chemical form of the trace metal, the leachability of the trace metal in the final particles, and if possible, the distribution of metal in the particles.

On a larger scale, UA will determine how both coal composition, detailed mineralogy and combustion conditions (including low $\mathrm{NO}_{\mathrm{x}}$ conditions) govern the fate of toxic metals under practical time/temperature, self sustained, yet still aerodynamically well defined, pulverized coal combustion conditions. Other tasks focus, one at a time, on individual aspects of toxic metal partitioning. In this task, experiments are performed with time-temperature profiles similar to those in pc combustors. Therefore, the hypothesis derived from the smaller scale facilities can be tested under 'real world' conditions to determine the dominant mechanisms for trace element partitioning. Results from this portion of the project, together with the other portions, will lead to a quantitative model that will predict the fate of all toxic species as functions of coal quality and combustion configurations.

Select coals will be burned in the UA self-sustained combustor under premixed conditions where all the coal is mixed with all the air prior to combustion. The baseline tests will employ the naturally occurring temperature profile for each coal at a stoichiometric ratio of 1.2. Samples will be withdrawn at the exhaust port. Complete impactor samples will be collected and analyzed for each toxic metal (11 as listed in the CAAA plus U and Th) plus major elements. This will yield the particle size segregated toxic metal composition, which can be compared to data obtained form other tasks of this program. This data will then be examined to determine particle size dependence in order to infer possible mechanisms governing the fate of each metal. 
Organic Emissions

Some organic emissions associated with coal combustors can have deleterious effects on the environment and/or human health. It is therefore very important (1) to know the identities, quantities, and toxicities of the organic species released from coal combustion systems, and (2) to understand the chemical and physical processes that govern these species' formation, destruction, and release. Organic emissions data from the DOE Air Toxics and EPRI PISCES programs have the potential of benefitting the evaluation of the problem of organic emissions from coal combustion. In Task 7, Princeton University is conducting a critical review of the available field data, focusing on (1) the appropriateness, thoroughness, and reliability of the experimental techniques employed; (2) comparison with previously published emissions data; (3) the implications of the results; (4) similarly evaluating comparable data available from other countries, particularly Europe and Australia; reviewing emerging technical literature on coal pyrolysis and combustion processes that affect organic emissions; (5) staying abreast of new results in the toxicity literature, relating to organic emissions from coal; and (6) communicating regularly with the other principal investigators of the air toxics team so that all will be cognizant of the ties between the organic and inorganic air toxics issues.

It is expected that the above efforts of analysis and literature review will lead to (1) comprehensive understanding of what is currently known about organic emissions from coal and (2) identification of the important questions that may still need to be addressed in future research.

\section{Model Validation}

Also under Task 7, the University of Connecticut is conducting a preliminary review of the relevant field data on inorganic emissions. In Phase I we will use the field data to focus the experimental program and to validate the models we will develop in Phase II. The Phase I effort focuses on data from the following sources:

- EPRI PISCES

- DOE Program

- VTT (Finland)

- KEMA (Netherlands)

Important issues to be addressed when reviewing these data include mass balance closure, methods of analysis and sample collection, effect of APCD, effect of bulk coal ash chemistry, particle size distribution, and speciation of $\mathrm{Hg}$.

\section{Model Development}

PSI will use its silicate equilibrium model accounts for the non-ideal behavior of multi component silicate solutions in combination with its trace element database to calculate $\mathrm{Cr}$ and As partitioning. These results will be compared with laboratory data generated under Tasks 5.1, $6.1,6.2$, and 8 , and inorganic species field data reviewed as part of Task 7. These calculations may be repeated for Se and/or other elements if experimental data warrant interpretation of vaporization under conditions where silicate chemistry is dominant. 
SECTION 3

RESULTS AND DISCUSSION

$3-1 / 3-2$ 


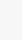




\section{RESULTS AND DISCUSSION}

\subsection{Program Management (PSD)}

During the last quarter the final program coal was procured and distributed to the team members. The coal, from the Wyodak seam in the Powder River Basin, was procured through a collaboration with another DOE-funded program at ABB. As with the program coals distributed earlier, all samples are stored under argon to prevent oxidation.

\subsection{Coal Characterization (UKy, USGS, PSD}

In the last quarter work continued on the characterization of the program coals, and the forms of occurrence of trace elements in these coals. Characterization of the Wyodak began late in the quarter. The standard coal analyses, Ultimate, Proximate, and Ash Chemistry, were completed for this coal and are presented in the following subsections. Characterization by more advanced techniques such as XAFS, CCSEM, and the USGS leaching protocol is underway. Much of the coal and trace element information for the Pittsburgh, Elkhorn/Hazard, and Illinois No. 6 coals was presented in the last Quarterly Report. ${ }^{2}$ Additional data on trace element forms of occurrence in these coals was obtained by both the USGS (leaching analysis) and the UKy group (XAFS analysis). These data are presented below.

\subsubsection{Ultimate, Proximate, and Ash Chemistry for Program Coals}

The results of Ultimate, Proximate, and Ash Chemistry analysis for the four program coals is shown in Table 3-1. As can be seen from this table the ash content for the Wyodak coal is similar to the other program coals. The moisture content is much higher for this coal than the bituminous coals. Moisture in the raw, crushed, coal obtained by ABB was much higher, approximately $30 \%$. The drop in moisture content indicates that the coal was dried during pulverization at ABB. Another parameter that is much different than the bituminous coals is the high calcium content of the Wyodak coal. This high calcium content, and low iron content, is typical of coals from the Powder River Basin. Experiments with this coal will provide valuable insight on the role of calcium on arsenic retention in the fly ash.

\subsubsection{Trace Element Forms of Occurrence in Coal - New Data}

As part of this program a wide array of analytical techniques and procedures are being utilized to determine the mode of occurrence of selected trace elements in coal. By utilizing complimentary analytical techniques we can determine both the physical association of the trace element (e.g., mineral or organically associated) and the chemical speciation (e.g., oxidation state) of the trace element in the coal.

During the last quarter data from the sequential leaching tests performed earlier in the program were obtained by the USGS. These sequential leaching tests utilized a procedure similar to that described by Palmer et al. ${ }^{3}$ which was modified from Finkelman et al. ${ }^{4}$ Duplicate $5 \mathrm{~g}$ samples were sequentially leached with $35 \mathrm{ml}$ each of $1 \mathrm{~N}$ ammonium acetate $\left(\mathrm{CH}_{3} \mathrm{COONH}_{3}\right)$, 
Table 3-1. Coal Properties for Program Coals

\begin{tabular}{|c|c|c|c|c|c|c|c|c|}
\hline & \multicolumn{2}{|c|}{ Elkhorn/Hazard } & \multicolumn{2}{|c|}{ Pittsburgh } & \multicolumn{2}{|c|}{ Illinois No. 6} & \multicolumn{2}{|c|}{ Wyodak } \\
\hline & $\begin{array}{l}\text { Dry } \\
\text { Basis }\end{array}$ & $\begin{array}{c}\text { As } \\
\text { Received } \\
\end{array}$ & $\begin{array}{c}\text { Dry } \\
\text { Basis }\end{array}$ & $\begin{array}{c}\text { As } \\
\text { Received } \\
\end{array}$ & $\begin{array}{c}\text { Dry } \\
\text { Basis } \\
\end{array}$ & $\begin{array}{c}\text { As } \\
\text { Received } \\
\end{array}$ & $\begin{array}{c}\text { Dry } \\
\text { Basis } \\
\end{array}$ & $\begin{array}{c}\text { As } \\
\text { Received } \\
\end{array}$ \\
\hline $\begin{array}{l}\text { Proximate (wt \%): } \\
\text { Fixed Carbon } \\
\text { Volatile Matter } \\
\text { Moisture } \\
\text { Ash }\end{array}$ & $\begin{array}{r}57.80 \\
34.61 \\
0.00 \\
7.59\end{array}$ & $\begin{array}{r}56.46 \\
33.80 \\
2.33 \\
7.41\end{array}$ & $\begin{array}{r}62.23 \\
30.66 \\
0.00 \\
7.11\end{array}$ & $\begin{array}{r}61.99 \\
30.22 \\
1.44 \\
7.01\end{array}$ & $\begin{array}{r}54.98 \\
34.41 \\
0.00 \\
10.61\end{array}$ & $\begin{array}{r}53.16 \\
33.27 \\
3.31 \\
10.26\end{array}$ & $\begin{array}{r}49.62 \\
41.91 \\
0.00 \\
8.47\end{array}$ & $\begin{array}{r}43.14 \\
36.44 \\
13.06 \\
7.36\end{array}$ \\
\hline $\begin{array}{l}\text { Ultimate (wt \%): } \\
\text { Carbon } \\
\text { Hydrogen } \\
\text { Nitrogen } \\
\text { Sulfur } \\
\text { Oxygen } \\
\text { Chlorine } \\
\text { Moisture } \\
\text { Ash }\end{array}$ & $\begin{array}{r}76.66 \\
4.70 \\
1.46 \\
0.84 \\
8.58 \\
0.17 \\
0.00 \\
7.59 \\
\end{array}$ & $\begin{array}{r}74.87 \\
4.59 \\
1.43 \\
0.82 \\
8.38 \\
0.17 \\
2.33 \\
7.41 \\
\end{array}$ & $\begin{array}{l}77.74 \\
4.87 \\
1.50 \\
1.66 \\
7.01 \\
0.099 \\
0.00 \\
7.11 \\
\end{array}$ & $\begin{array}{c}76.62 \\
4.80 \\
1.48 \\
1.64 \\
6.91 \\
0.098 \\
1.44 \\
7.01 \\
\end{array}$ & $\begin{array}{c}70.02 \\
4.89 \\
1.22 \\
3.72 \\
9.50 \\
0.035 \\
0.00 \\
10.61 \\
\end{array}$ & $\begin{array}{c}67.70 \\
4.73 \\
1.18 \\
3.60 \\
9.20 \\
0.034 \\
3.31 \\
10.26 \\
\end{array}$ & $\begin{array}{r}61.19 \\
5.28 \\
0.95 \\
0.25 \\
23.86 \\
* * \\
0.00 \\
8.47 \\
\end{array}$ & $\begin{array}{r}53.20 \\
4.59 \\
0.83 \\
0.22 \\
20.74 \\
* * \\
13.06 \\
7.36 \\
\end{array}$ \\
\hline $\begin{array}{l}\text { Ash Composition (wt\%): } \\
\mathrm{SiO}_{2} \\
\mathrm{Al}_{2} \mathrm{O}_{3} \\
\mathrm{Fe}_{2} \mathrm{O}_{3} \\
\mathrm{TiO}_{2} \\
\mathrm{CaO} \\
\mathrm{MgO} \\
\mathrm{Na}_{2} \mathrm{O} \\
\mathrm{K}_{2} \mathrm{O} \\
\mathrm{SO}_{3} \\
\mathrm{P}_{2} \mathrm{O}_{5}\end{array}$ & \multicolumn{2}{|c|}{$\begin{array}{r}55.83 \\
34.27 \\
5.18 \\
1.71 \\
1.84 \\
0.60 \\
0.32 \\
1.53 \\
1.45 \\
0.23 \\
\end{array}$} & \multicolumn{2}{|c|}{$\begin{array}{r}42.92 \\
22.87 \\
19.18 \\
1.08 \\
4.51 \\
0.97 \\
1.28 \\
1.21 \\
5.40 \\
0.57 \\
\end{array}$} & \multicolumn{2}{|c|}{$\begin{array}{r}44.38 \\
17.35 \\
19.80 \\
0.91 \\
4.00 \\
0.85 \\
0.63 \\
1.80 \\
4.62 \\
0.12 \\
\end{array}$} & \multicolumn{2}{|c|}{$\begin{array}{r}31.76 \\
18.04 \\
5.81 \\
1.80 \\
24.35 \\
2.61 \\
0.90 \\
0.70 \\
12.93 \\
1.10 \\
\end{array}$} \\
\hline
\end{tabular}


3N hydrochloric acid (HCL), concentrated hydrofluoric acid (HF; 48\%) and 2N (1:7) nitric acid $\left(\mathrm{HNO}_{3}\right)$ in $50 \mathrm{ml}$ polypropylene tubes. Lach tube was shaken for $18 \mathrm{~h}$ on a Burrell ${ }^{\mathrm{a}}$ wrist action shaker. Because of the formation of gas during some of the leaching procedures it was necessary to enclose each tube in two polyethylene bags, each closed with plastic coated wire straps that allow gas to escape but prevent the release of liquid. Approximately $0.5 \mathrm{~g}$ of residual solid was removed from each tube for instrumental neutron activation analysis (INAA). The solutions were saved for inductively coupled argon plasma (ICP) analysis. The leaching results for the trace elements are discussed individually below. The raw leaching data, including selected major elements, can be seen in the USGS progress report in Appendix A.

The group at UKy is using XAFS spectroscopy and Mössbauer spectroscopy to complement the USGS work, and to examine the mode of occurrence of key HAPs and other elements in program coals. As discussed in the first Quarterly Report, ${ }^{5}$ the XAFS spectra of the HAPs elements are obtained not just from the raw coal (RAW), but also from three fractions: (1) an "organic-rich" fraction (ORG) - either the fraction that floats in a 1.62 specific gravity liquid or the clean product from a Denver (froth flotation) cell; (2) a neavy-minerals-rich" fraction (HYM) - the fraction of the refuse or tailings fraction from (1) that sinks in a 2.875 specificgravity liquid; and (3) a "clay-rich" fraction (CLAY) - the float fraction from the 2.875 specificgravity liquid. These fractions are then taken to the synchrotron for XAFS analysis. It should be noted that the approximate weight ratios of the different fractions separated from these coals according to this scheme are estimated to be: ORG:CLAY:HYM $=>90 \%: 5$ to $10 \%:<1 \%$, depending on ash content. During the last quarter, new XANES data were obtained at Stanford Synchrotron Radiation Laboratory (SSRL), Palo Alto, CA, on Se and $\mathrm{Zn}$ in the program coals and the float/sink fractions.

New data for the individual elements are discussed separately below.

\section{Arsenic:}

Leaching data for arsenic in three of the program coals can be seen in Table 3-2. Because arsenic in the Pittsburgh and Illinois No. 6 coals was leached primarily by nitric acid, we infer the association of arsenic with pyrite. The association of arsenic with pyrite in these coals was confirmed by microprobe analyses (see Appendix A). In the Elkhorn/Hazard coal, arsenic behaves in a manner similar to that of iron; that is, arsenic is leached primarily by hydrochloric acid. It is possible that pyrite grains with high concentrations of arsenic (approximately $2 \mathrm{wt} \%$ ) in the Elkhorn/Hazard were more readily oxidized than grains with low concentrations of arsenic (100 ppm arsenic). However, the arsenic data are incomplete, as indicated by low total percentages for arsenic in the four leachates (about $40 \%$ ) and additional data are needed before a definite determination can be made. Comparison of the XAFS data and the leaching results suggest that the unleached arsenic may be derived from fine pyrite grains included in the carbon matrix. The carbon matrix may serve to shield the pyriie grains from the leaching solutions. To

${ }^{a}$ Use of tradenames and trademarks in this publication is for descriptive purposes only and does not constitute endorsement by the U.S. Geological Survey. 
Table 3-2. Mean Percentages of Arsenic Leached (Error $\pm 25 \%)^{*}$

\begin{tabular}{|c|c|c|c|c|c|}
\hline \multirow{2}{*}{ Coal } & \multicolumn{4}{|c|}{ Percent Leached by Each Solution } & \multirow{2}{*}{$\begin{array}{c}\text { Percent } \\
\text { Remaining }\end{array}$} \\
\hline & Am. Ac. & $\overline{\mathrm{HCL}}$ & $\mathrm{HF}$ & $\mathrm{HNO}_{3}$ & \\
\hline Pittsburgh & 1 & 11 & 5 & 57 & 26 \\
\hline Elkhorn/Hazard & 1 & 29 & 6 & 4 & 60 \\
\hline Illinois No. 6 & 1 & 19 & 5 & 40 & 35 \\
\hline
\end{tabular}

${ }^{*}$ All data are rieliminary and subject to revision as new data become available.

test this conclusion, future work may involve the examination of solid residue from the nitric acid leach to determine if some of the arsenic was not leached.

\section{Selenium:}

As discussed in the last Quarterly Report, ${ }^{2}$ the selenium custents of the Elkhorn/Hazard and Illinois \#6 coals are relatively high ( 2 to $3 \mathrm{ppm}$ ), whereas the Se content of the Pittsburgh coal is less than $1 \mathrm{ppm}$. Based on these high concentrations, and on some favorable preliminary data obtained earlier on the Elkhorn/Hazard coal, it was felt that a detailed XANES examination of Se in the Illinois \#6 and Elkhorn/Hazard coals would be worthwhile. No examination of Se in the Pittsburgh coal or its fractions has been attempted.

Selenium K-edge XANES data were collected at SSRL over the energy range from $100 \mathrm{eV}$ below the Se K-edge at 12,658 eV to about $300 \mathrm{eV}$ above the edge. The XANES spectra, prepared from the raw XAFS spectra, are shown as Figures 3-1 and 3-2 for the Pittsburgh and Elkhorn/Hazard coals and fractions, respectively. The Se XANES spectrum obtained for the Pittsburgh 2.88 sink fraction has the best signal/noise ratio of any of the spectra in Figures 3-1 and 3-2 and, furthermore, it strongly resembles the XANES spectrum from As in the same fraction. Hence, most, if not all, of the Se in this 2.88 fraction is present as Se anions substituting for sulfur in the pyrite structure, in similar fashion to As. The Se XANES spectra of the raw and 1.62 float fractions of the Illinois \#6 coal, although much noisier than that of the 2.88 sink fraction, appear to be similar to that of the pyrite-rich fraction. However, there is the presence of a small peak at about $8 \mathrm{eV}$ in these two fractions that complicates the comparison; this peak arises from selenate $\left(\mathrm{SeO}_{4}{ }^{2-}\right)$ species and is not observable on the 2.88 sink fraction. Again, when we compare these observations on Se to the arsenic data for the same coal, we find the corresponding arsenate $\left(\mathrm{AsO}_{4}{ }^{3-}\right)$ species present in the raw coal and float fractions, but absent from the 2.88 sink fraction. Hence, there is a strong correlation between the occurrence of As and Se in the Illinois \#6 coal and both of these elements appear to be predominantly associated with pyrite.

The 2.88 sink fraction for Elkhorn/Hazard is similar to that observed for the Illinois \#6 coal, and we conclude that most of the Se in this fraction is also associated with pyrite.

However, because the spectrum is less defined than that of the Illinois \#6 coal fraction, it is possible that other Se forms may also be contributing to this spectrum. In contrast to the Illinois \#6 situation, the Se XANES of the column float fraction lacks any features that can be attributed to $\mathrm{Se}$ in pyrite. Furthermore there is a weak peak at about $18 \mathrm{eV}$, present also in the spectrum of 


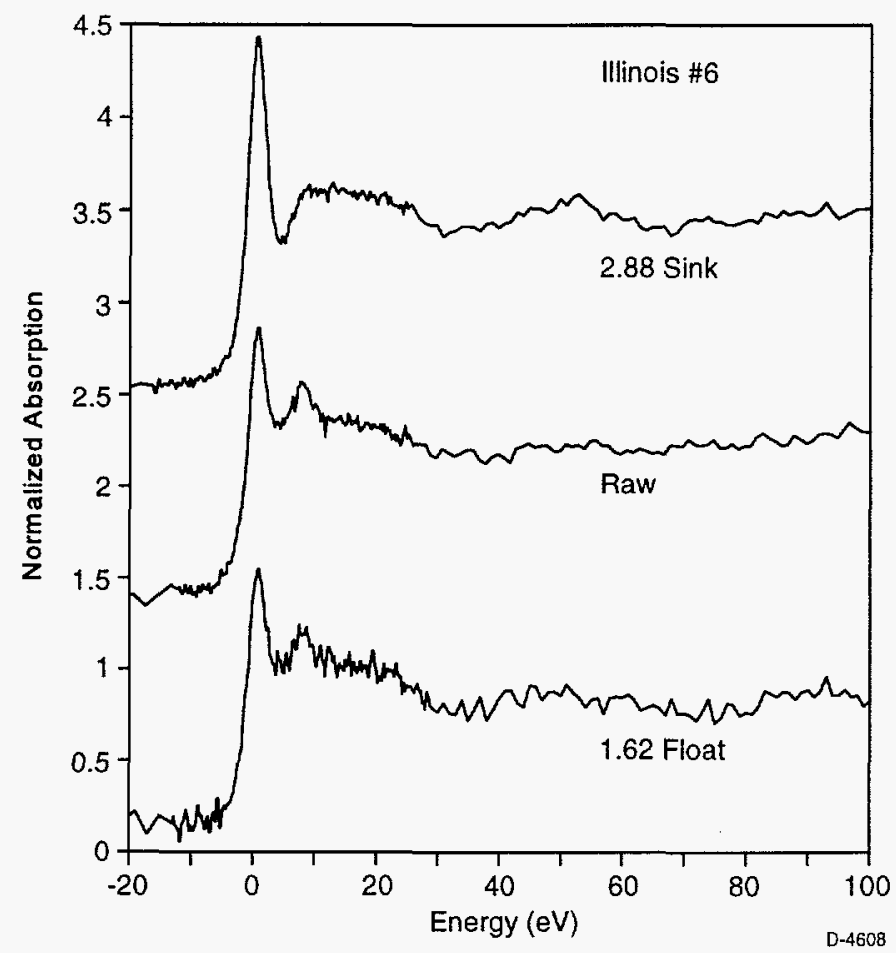

Figure 3-1. Se XANES of raw Illinois No. 9 coal and float/sink fractions.

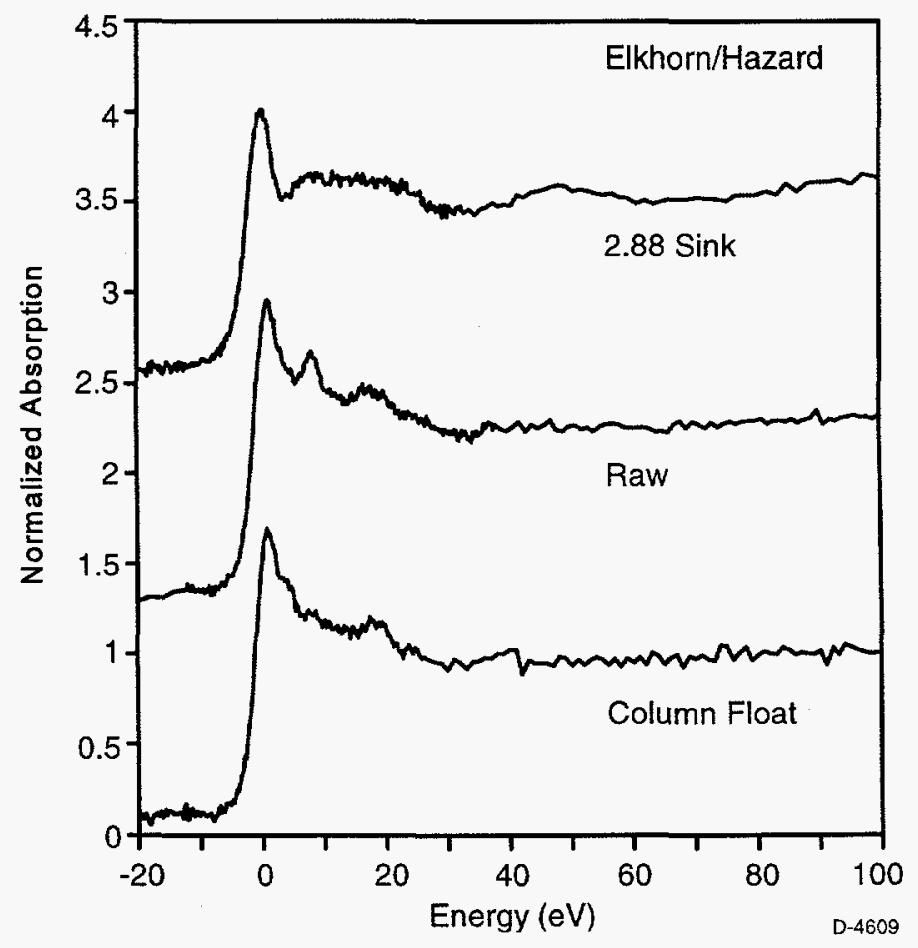

Figure 3-2. Se XANES of raw Elkhorn/Hazard coal and float/sink fractions. 
the raw coal, that clearly must arise from another form of Se than Se in pyrite. We interpret this spectrum as arising from an organoselenium form in the column float fraction.

The data on relative step-heights (Table 3-3) are also quite revealing. In the case of As and $\mathrm{Se}$ in the Illinois \#6 coal, there is a close correspondence between the step-heights for these two elements in the different fractions. For Elkhorn/Hazard, however, the As step-height data for the different fractions show more variation than the data for Se. This difference would also suggest that Se and As are not as closely associated in the Elkhorn/Hazard coal as appears to be the case for the Illinois \#6 coal. Hence, we interpret these observations to indicate that in the Elkhorn/Hazard coal there is a significant selenium form that is not duplicated by arsenic and does not segregate between fractions. Again an organoselenium form is indicated. Owing to the small fraction of pyrite in the Elkhorn/Hazard coal, it is likely that the organoselenium form is the major form of Se in this coal since the Se step-height for the pyrite fraction is only 2.5 times that of the float fraction.

Table 3-3. Comparison of As and Se Step-Heights and wt \% Pyritic Sulfur for Elkhorn/Hazard and Illinois \#6 Coals

\begin{tabular}{|c|c|c|c|}
\hline Coal Sample Fraction & $\begin{array}{c}\text { Arsenic } \\
\text { Step-Height }\end{array}$ & $\begin{array}{c}\text { Selenium } \\
\text { Step-Height }\end{array}$ & $\begin{array}{c}\text { wt \% S as } \\
\text { Pyritic }\end{array}$ \\
\hline \hline $\begin{array}{c}\text { Elkhorn/Hazard } \\
\text { ORG }\end{array}$ & 0.6 & 0.9 & 0.12 \\
\hline RAW & 1.0 & 1.0 & 0.15 \\
\hline CLAY & 2.1 & -- & 0.40 \\
\hline HYM & 4.0 & 2.0 & 12.6 \\
\hline Illinois \#6 & 0.75 & 0.8 & 0.71 \\
\hline ORG & 1.0 & 1.0 & 1.45 \\
\hline RAW & 4.0 & -- & 9.60 \\
\hline CLAY & 6.0 & 5.0 & 34.0 \\
\hline HYM & & &
\end{tabular}

\section{Zinc:}

Although zinc is not one of the HAP elements listed in the 1990 Clean Air Act Amendments, a brief investigation into the mode of occurrence of zinc in the program coals has been undertaken because of the high concentration of zinc, approximately $70 \mathrm{ppm}$, in the Illinois \#6 coal, and also because experiments carried out at MIT, reported in the last Quarterly Report, ${ }^{2}$ indicated the vaporization behavior of zinc to be somewhat variable among the three coals.

Zinc XANES spectra were obtained for all three coals and for the float/sink fractions from the Illinois \#6 coal. The zinc XANES for the Illinois \#6 coal and fractions are shown in Figure 3-3. These spectra show significant variation, particularly for the two extreme fractions, 


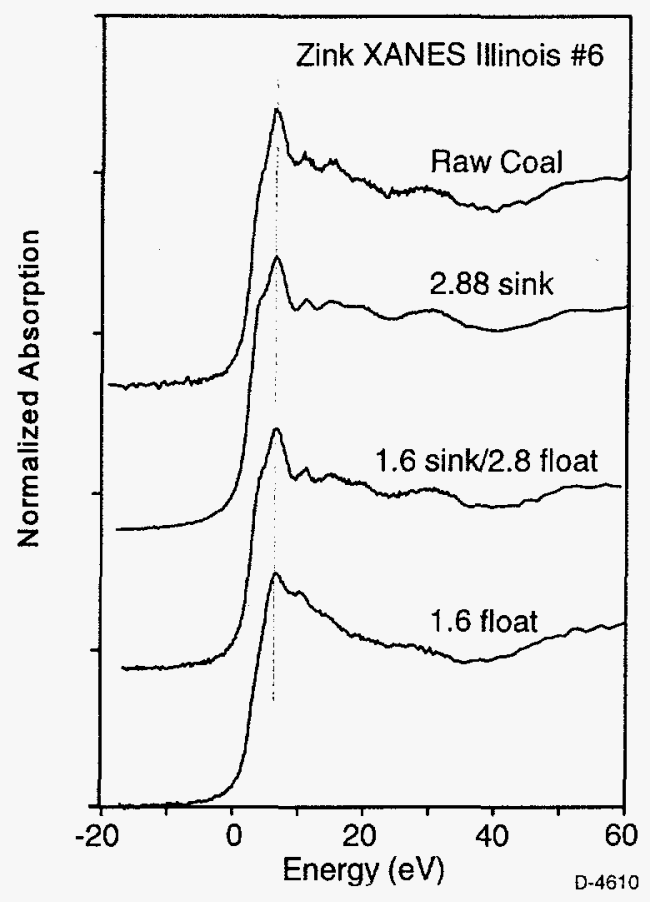

Figure 3-3. Zn XANES of raw Illinois No. 9 coal and float/sink fractions.

the 2.88 sink and 1.62 float. The spectrum of the 2.88 sink fraction can be readily identified as arising from sphalerite, $\mathrm{ZnS}$; this should be no surprise because zinc-bearing minerals, especially sulfides, are well known to be a characteristic feature of coal seams from Illinois. However, it is clear from the spectra in Figure 3-3 that not all of the zinc in this sample of Illinois \#6 coal is present in this form. In particular, the $\mathrm{Zn}$ XANES spectrum of the 1.62 float fraction is significantly different, while the spectra of the intermediate fraction ( $1.6 \operatorname{sink} / 2.88$ float) and raw coal appear to be composites of the two extreme spectra. At this time, it is not clear what the dominant form of zinc present in the float fraction might be.

A comparison of the zinc XANES spectra of the three coals is shown in Figure 3-4. Whereas the spectrum of the Illinois \#6 coal appears to be dominated by $\mathrm{Zn}$ in the form of $\mathrm{ZnS}$, it is clear that $\mathrm{ZnS}$ is not present to any significant degree in the other two coals. Again, although the precise form of zinc in these other two coals is not apparent at this time, it is possible that the zinc may be in oxygen coordination based on the shift of the main peak.

\subsection{Combustion Zone Transformations (PSI, MIT, UKy)}

Work on the transformations of trace elements in the combustion zone is proceeding along two major fronts. In the first area investigators at PSI and UKy are working to determine how the oxidation state of pyrite and arsenic influence trace element vaporization in the combustion zone. In the second area investigators at MIT are working with the size and density segregated coals and a droptube reactor to evaluate vaporization behavior of trace elements. This work is expanded upon at PSI where investigators at PSI are using the utility grind coal and the PSI EFR to determine the net vaporization of trace elements in the combustion zone. 


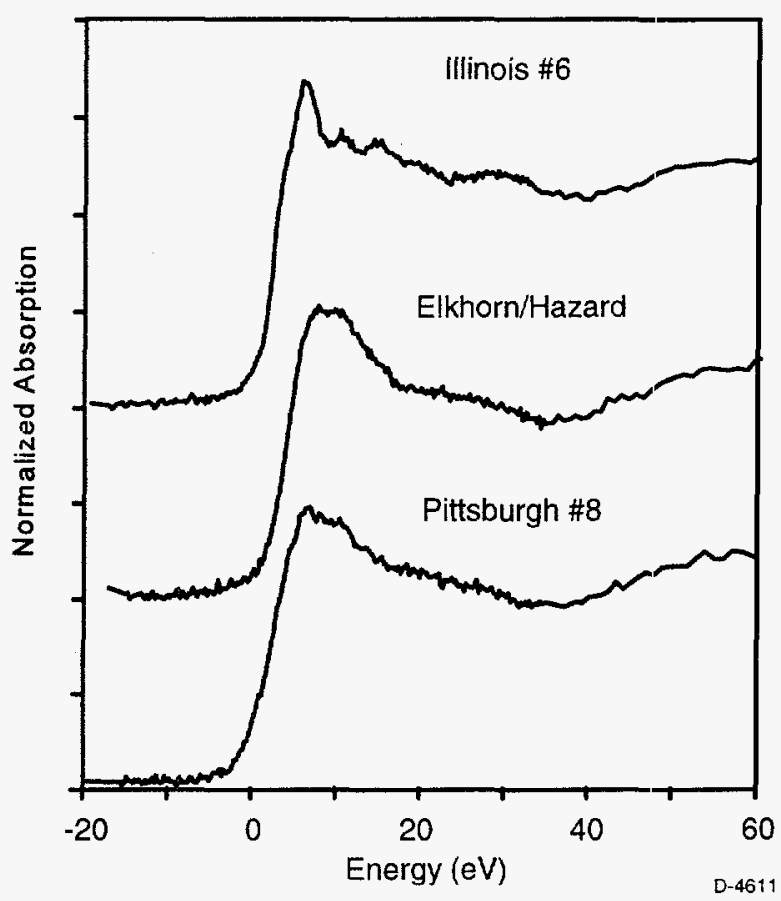

Figure 3-4. Zn XANES of raw Elkhorn/Hazard coal and float/sink fractions.

\subsubsection{The Effect of Coal Oxidation on Trace Element Vaporization in the Combustion Zone}

Arsenic has been reported to be quite variable in how it partitions between fly ash and bottom ash fractions in the combustion process and it has been proposed that it is the mode of occurrence of the arsenic in the coal that is the cause of the variability. As a result, at the Project Review meeting held in Pittsburgh in September 1996, it was agreed by researchers at PSI and at UKy to explore this question further. To do this, and to explore how pyrite oxidation may affect vaporization of other species commonly associated with pyrite (e.g., selenium), an experiment was designed to alter the oxidation state of the pyrite in the coal and then measure the vaporization of trace elements in the oxidized coal. Oxidation of the coal is currently underway at UKy by simulating natural weathering to oxidize the pyrite.

Three samples of approximately $1200 \mathrm{~g}$ of the Illinois \#6 coal were laid out in trays. Two of the trays were placed in a laboratory oven at $50^{\circ} \mathrm{C}$, while the third tray was located in a quiet corner of the laboratory at ambient conditions $\left(20^{\circ} \mathrm{C}\right)$. A beaker of water was also placed in the oven to ensure a moist atmosphere. The beaker was periodically refilled until the coal was saturated. At that point the source of water was removed and the coal allowed to dry. After 60 days, a sample of the coal was taken from the oven and subjected to Mössbauer spectroscopy to determine the extent of oxidation of the iron. The Mössbauer spectrum is shown in Figure 3-5 and indicates, in comparison to data for the fresh coal reported in the last quarter's report, that about $50 \%$ of the iron has been oxidized. The main product is the ferrous sulfate szomolnokite $\left(\mathrm{FeSO}_{4} \cdot \mathrm{H}_{2} \mathrm{O}\right)$ with a minor amount of jarosite formed as well. At 90 days, one tray will be removed and the coal will be shipped to PSI for combustion testing. A small sample will be retained at UKy for Mössbauer and XAFS determinations of the iron and arsenic oxidation states. 


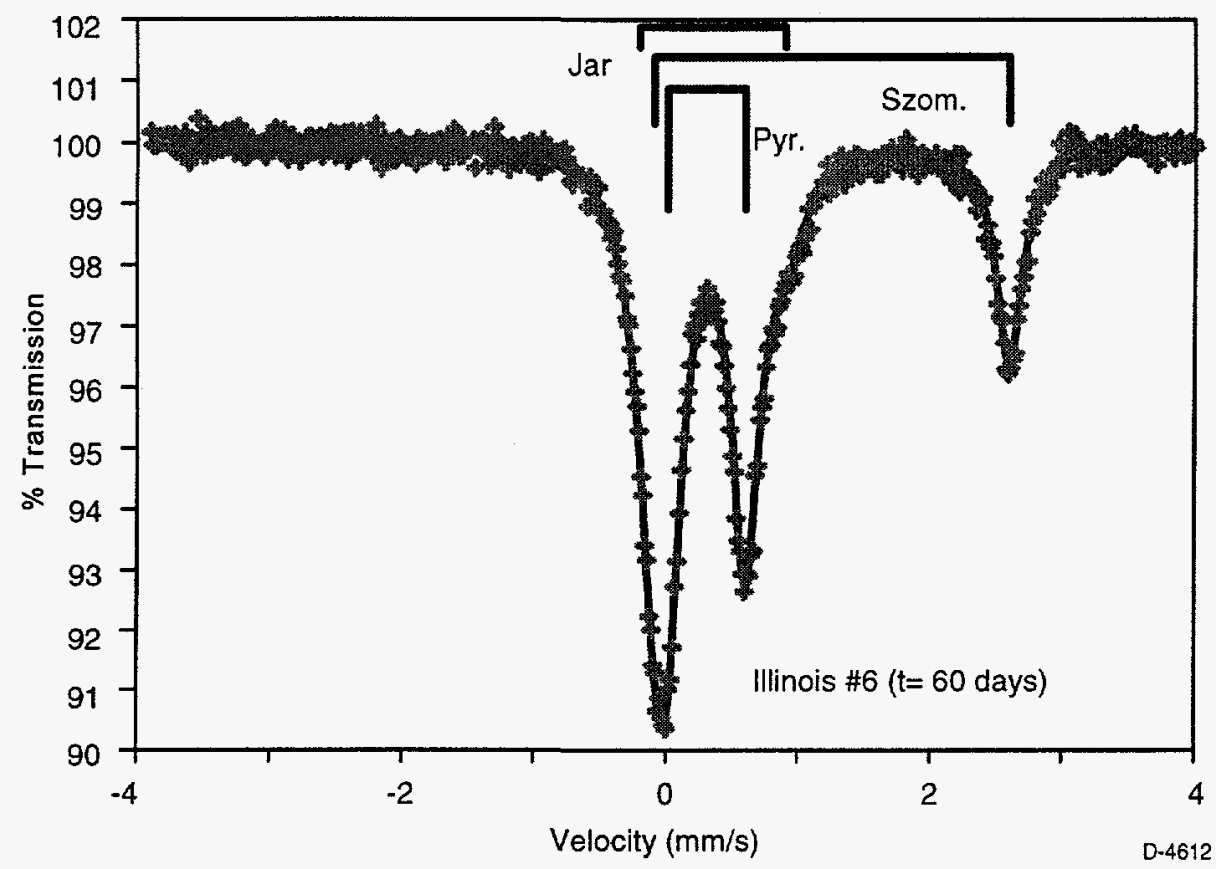

Figure 3-5. Mossbauer spectrum of Illinois No. 6 "weathered" for 60 days at $50^{\circ} \mathrm{C}$.

\subsubsection{Trace Element Vaporization in the Combustion Zone}

During the last quarter baseline combustion experiments on the PSI EFR were completed for the three bituminous coals. The coals were combusted at a stoichiometric ratio of 1.2, with air as the combustion gas. The furnace setpoint was $1500^{\circ} \mathrm{C}$, yielding a maximum gas temperature of $1450^{\circ} \mathrm{C}$. Size segregated ash samples were collected with a water-cooled nitrogen quench probe and a cascade impactor. As can be seen from Figures 3-6 and 3-7 the ash particle size distribution from the Illinois No. 6 is slightly finer than the other two coals. The data in Figures 3-8 and 3-9 show that the ash generated from the Elkhorn/Hazard coal at fuel rich conditions was very similar in size to that generated under fuel lean conditions. A similar trend was noted for the Pittsburgh coal (Figures 3-10 and 3-11).

Based on INAA of the size segregated ash samples, it was possible to estimate the fractional vaporization of any given element, defined as the fraction of that element found in the submicron ash. Figure 3-12 shows the effect of combustion conditions on the trace element vaporization in the Elkhorn/Hazard coal. These data suggest that the combustion conditions, fuel rich or fuel lean, may play a major role in trace element vaporization. The reason for the decreased vaporization of all elements at lower stoichiometric ratios is unclear, but may include lower particle temperatures and increased oxidation times for inherent pyrite particles. If, as was suggested in the last Quarterly Report, ${ }^{2}$ the vaporization of pyrite-associated species, such as arsenic, is linked to the oxidation of the pyrite, the lower oxidation of the pyrite would lead to the observed decrease. This trend is also seen in the data for the Pittsburgh coal. Figure 3-13 sho'vs the effect of combustion conditions on trace element vaporization in the Pittsburgh coal. Data from a Pittsburgh coal in an earlier program (denoted as $1.2^{*}$ ) are also shown. It is interesting to note that the fractional vaporization under fuel lean conditions for both Pittsburgh coals is qualitatively similar. 


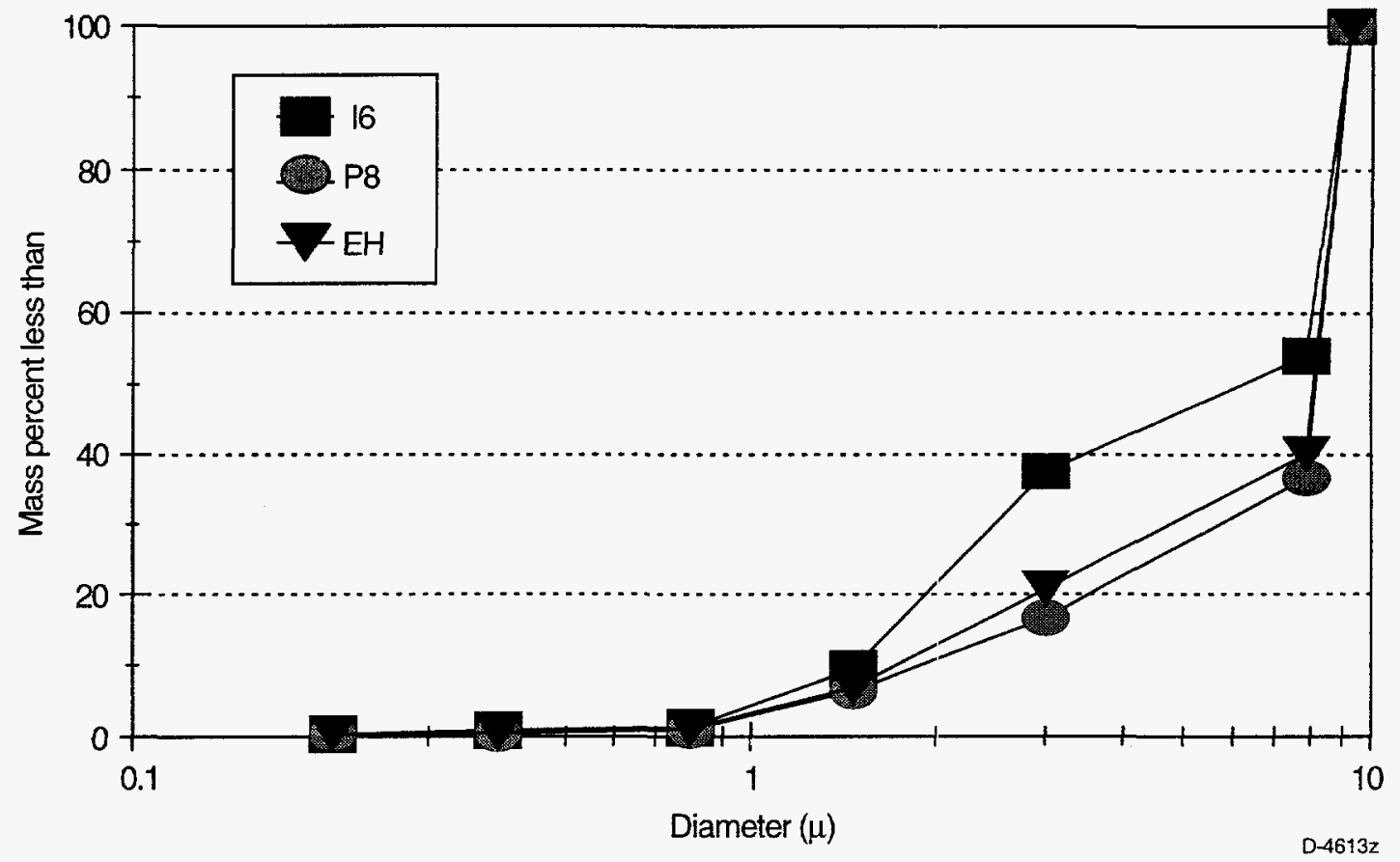

Figure 3-6. Cumulative ash particle size distributions for three bituminous coals (PSI EFR, $1.6 \mathrm{~s}$ residence time, $1500{ }^{\circ} \mathrm{C}$, Stoichiometric ratio of 1.2 ).

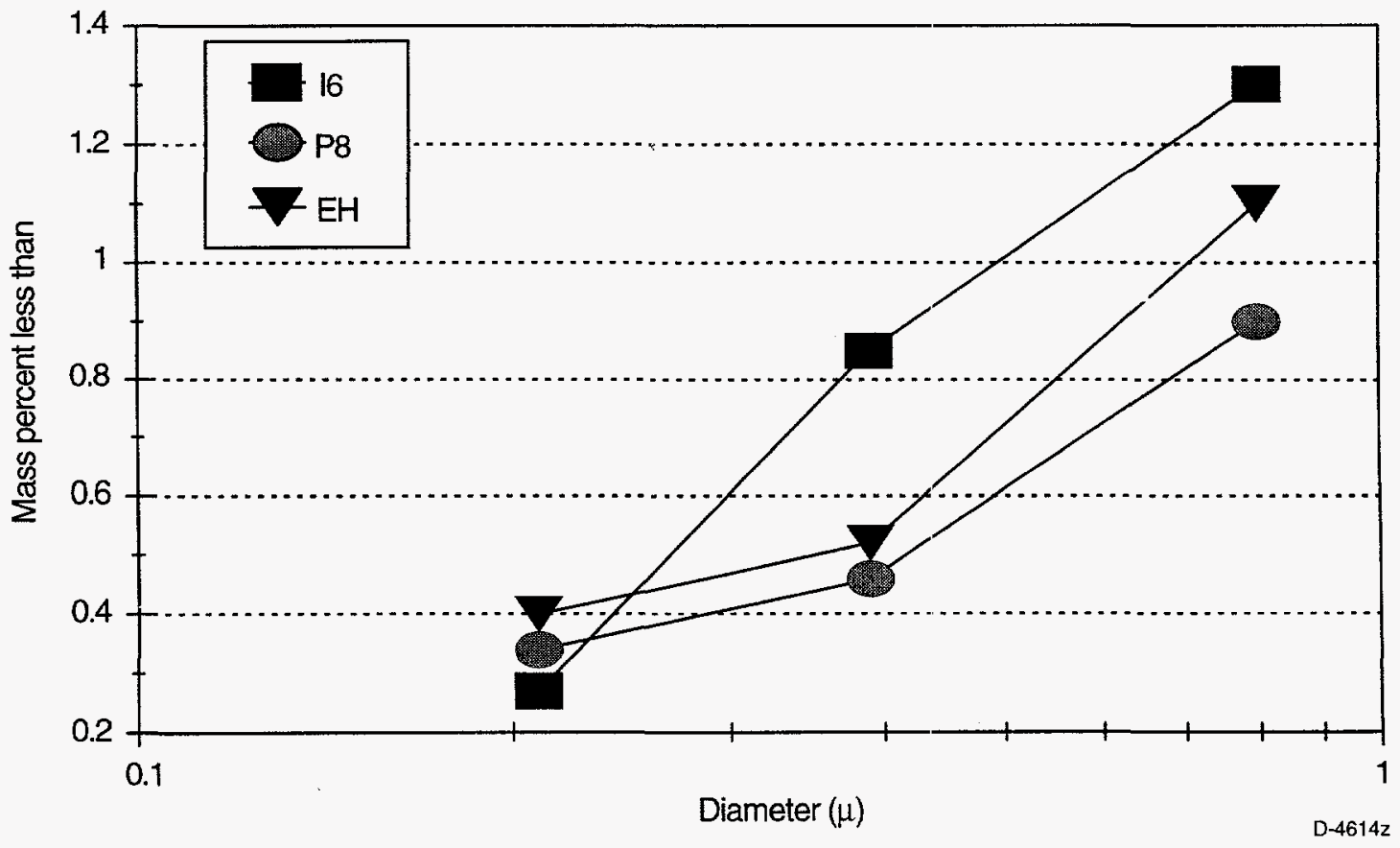

Figure 3-7. Cumulative submicron ash particle size distributions for three bituminous coals (PSI EFR, $1.6 \mathrm{~s}$ residence time, $1500^{\circ} \mathrm{C}$, Stoichiometric ratio of 1.2 ). 


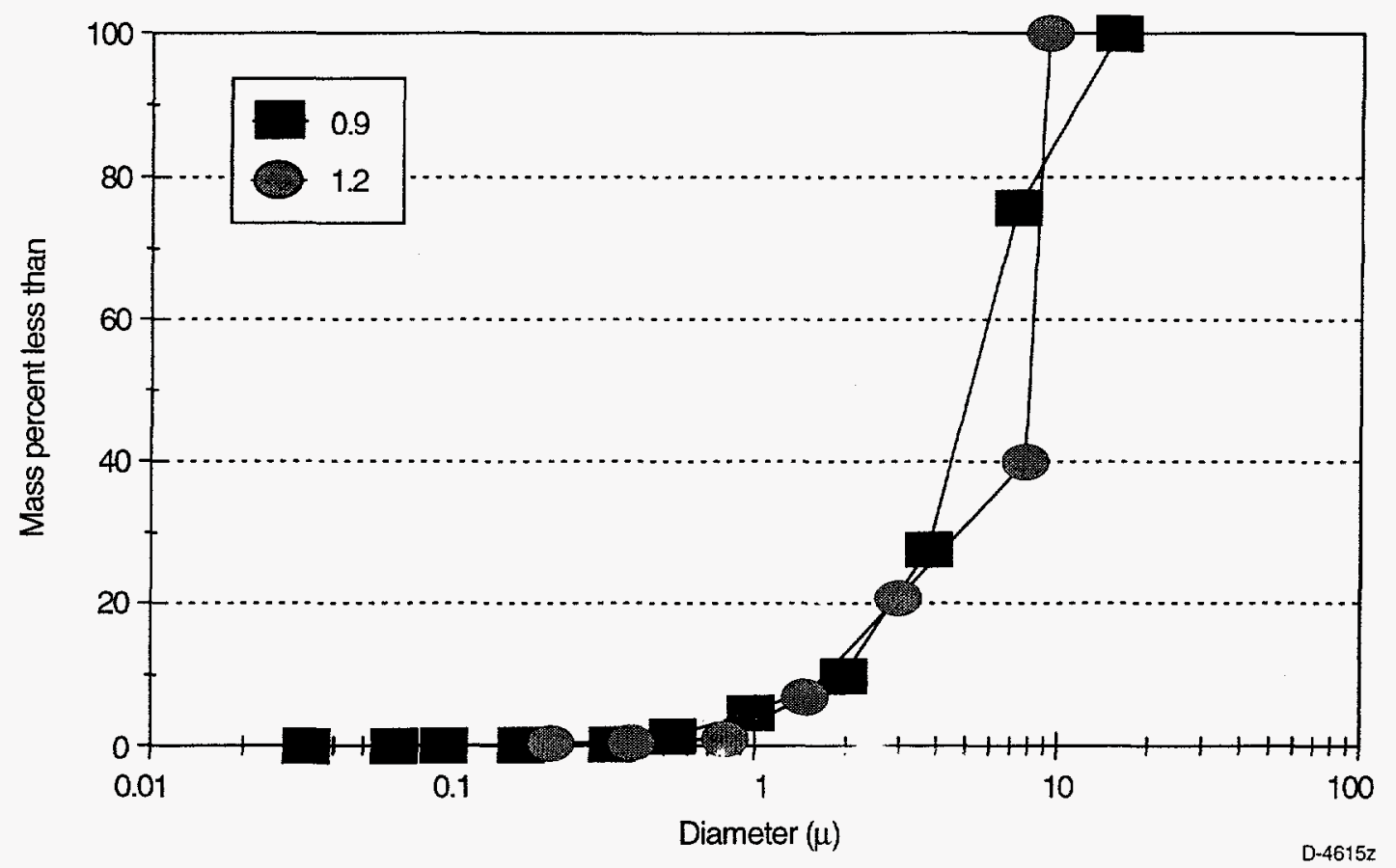

Figure 3-8. Cumulative ash particle size distributions for Elkhorn/Hazard at different stoichiometric ratios (PSI EFR, $1.6 \mathrm{~s}$ residence time, $1500^{\circ} \mathrm{C}$ ).

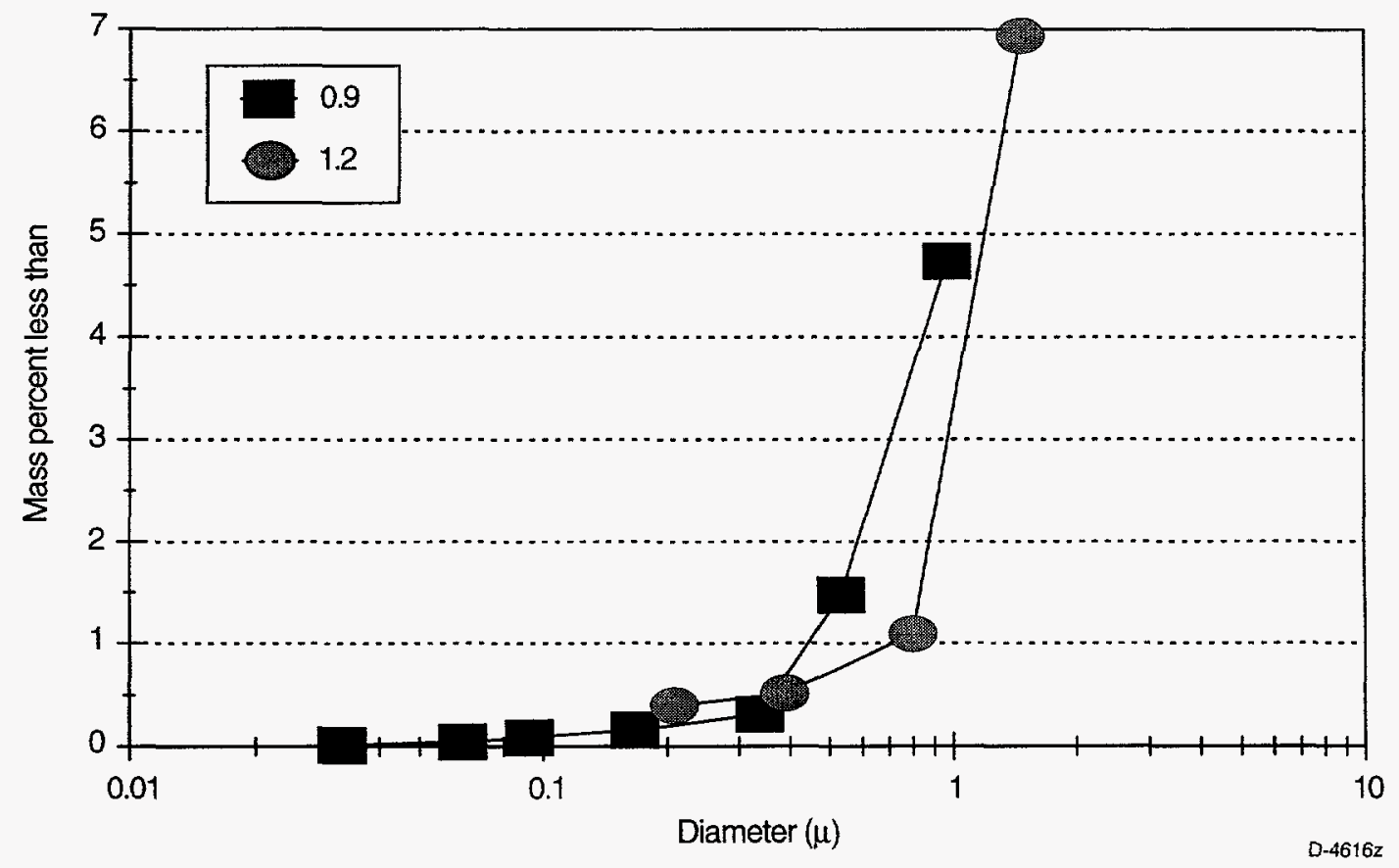

Figure 3-9. Cumulative submicron ash particle size distributions for Elkhorn/Hazard at different stoichiometric ratios (PSI EFR, $1.6 \mathrm{~s}$ residence time, $1500^{\circ} \mathrm{C}$ ). 


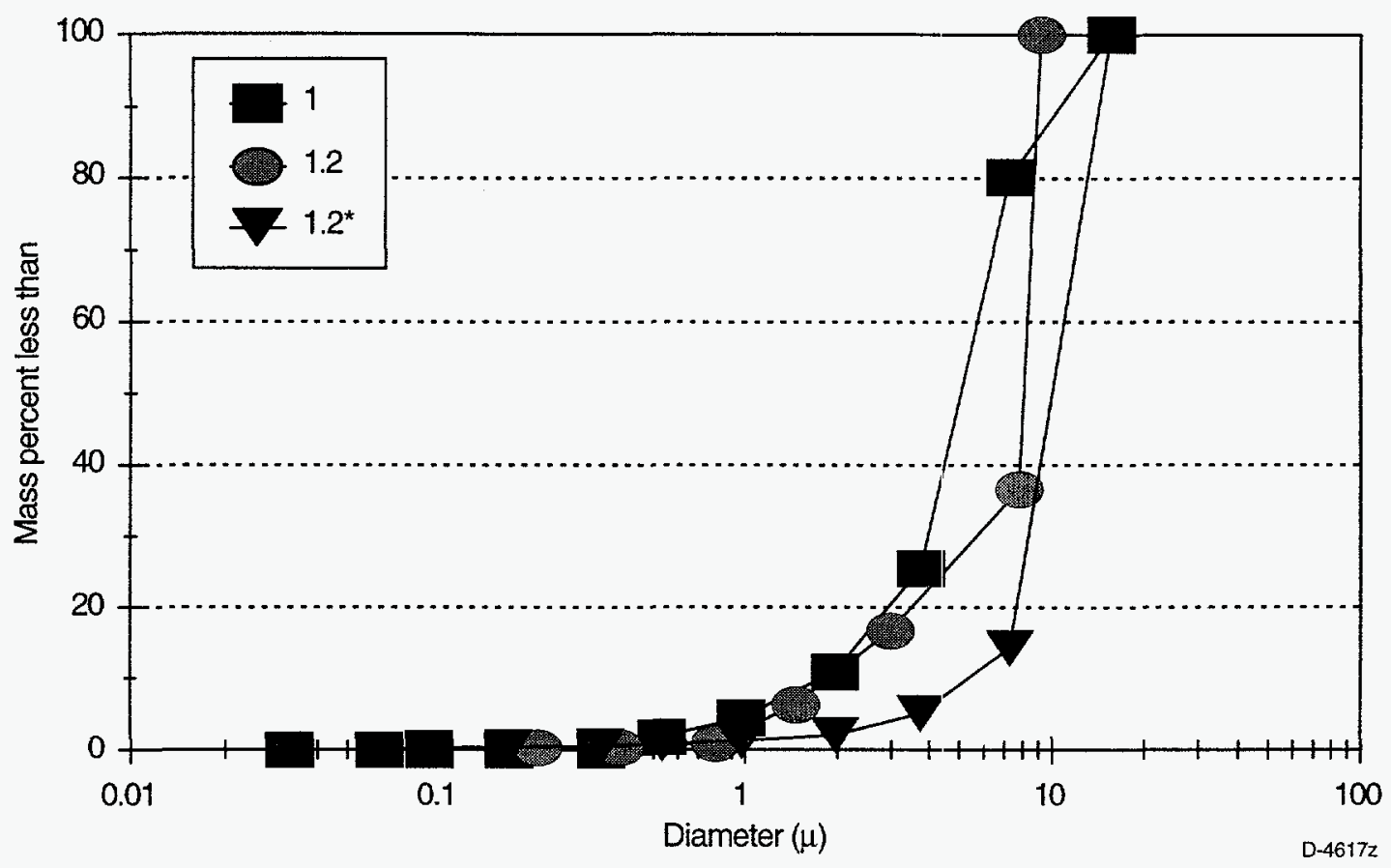

Figure 3-10. Cumulative ash particle size distributions for the Pittsburgh coal at different stoichiometric ratios (PSI EFR, $1.6 \mathrm{~s}$ residence time, $1500^{\circ} \mathrm{C}$ ).

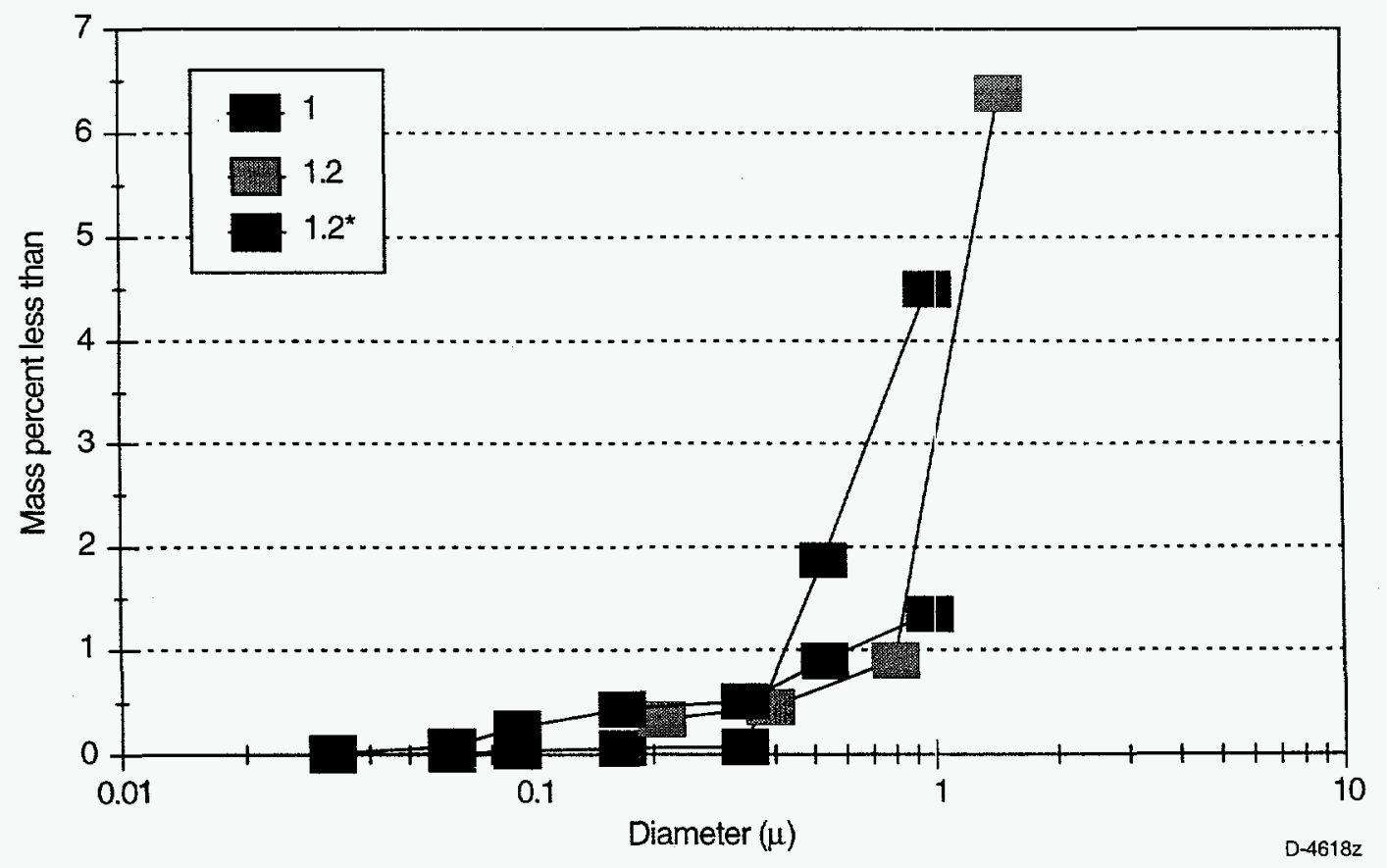

Figure 3-11. Cumulative submicron ash particle size distributions for the Pittsburgh coal at different stoichiometric ratios (PSI EFR, $1.6 \mathrm{~s}$ residence time, $1500^{\circ} \mathrm{C}$ ). 


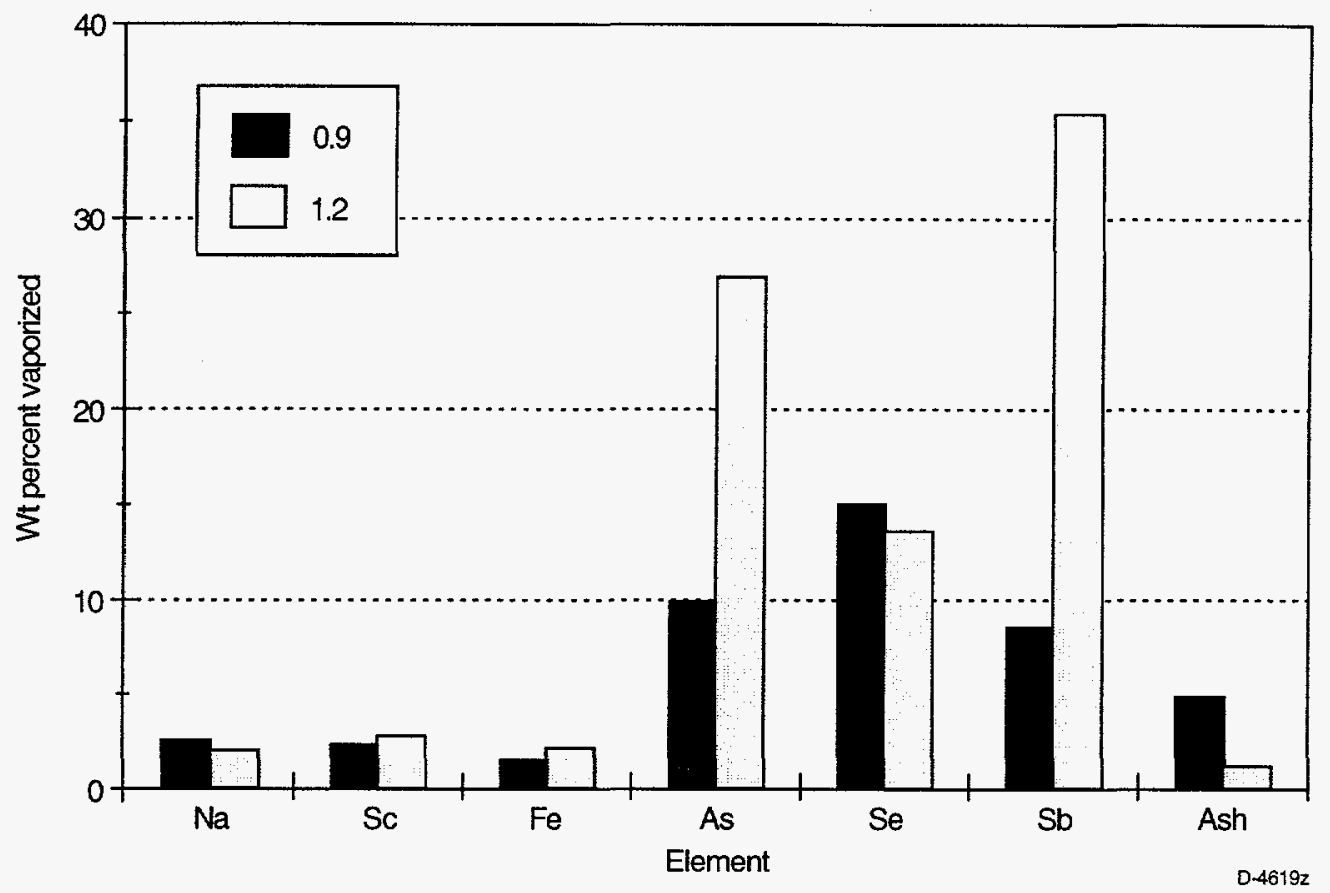

Figure 3-12. Fractional vaporization for several elements in the Elkhorn/Hazard coal at different stoichiometric ratios (PSI EFR, $1.6 \mathrm{~s}$ residence time, $1500^{\circ} \mathrm{C}$ ).

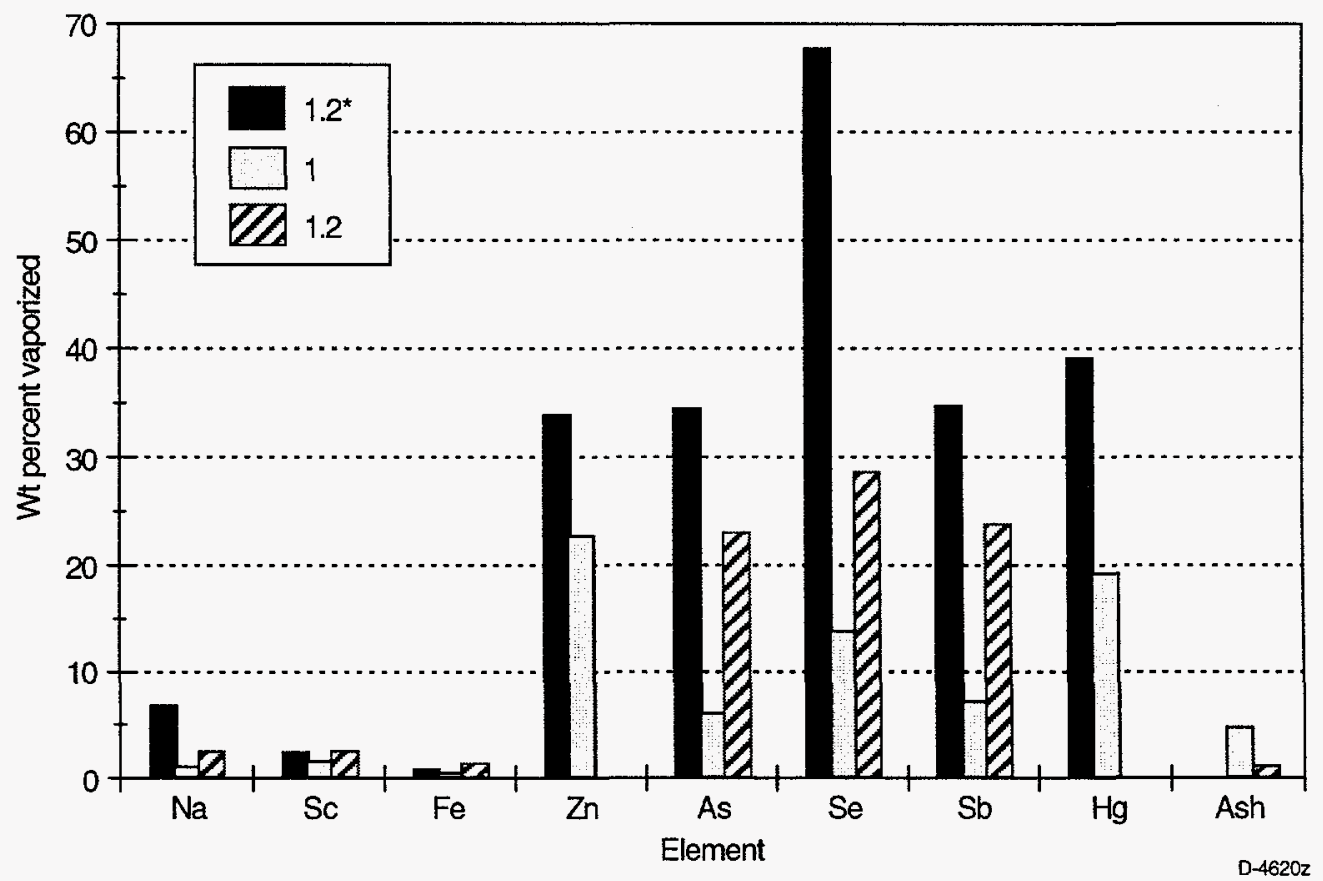

Figure 3-13. Fractional vaporization for several elements in the Elkhorn/Hazard coal at different stoichiometric ratios (PSI EFR, $1.6 \mathrm{~s}$ residence time, $1500^{\circ} \mathrm{C}$ ). 
Although these data qualitatively support the pyrite oxidation hypothesis, more data are required to better understand the effect of reducing conditions on trace element vaporization. Collection of these data at both PSI and MIT is underway.

Additional data on ash vaporization were obtained for density and size segregated samples of the Pittsburgh, Illinois \#6, and Elkhorn/Hazard (referred to as KY on the figures) in the MIT drop tube furnace. The combustion conditions were selected to yield volatilization amounts comparable to those encountered in utility boilers. For a drop tube operated at $1700 \mathrm{~K}$, the heat losses to the walls are larger than for the near adiabatic conditions in the center of a large scale boiler. In order to compensate for the effect of the radiative heat transfer to the walls on the particle combustion temperature, a value of $20 \%$ was selected for the oxygen concentration. These conditions had been previously used by Quann et al. ${ }^{1}$ in a 20 -coal study. The results from the previous study, while providing interesting trends on the extent of the vaporization and condensation of different elements, were for coals for which detailed mineral characterization was not available. The results of the present study will have the advantage of the detailed coal characterization to support the combustion studies. In this progress report the data from this study are compared with the Quann et al. ${ }^{1}$ study in order to determine the effects of size and density segregation on vaporization behavior. The results for selected elements are presented below. For each element, the data on the amount of the element collected in the submicron aerosol is plotted on the ordinate, and the amount of the element in the coals plotted on the abscissa. A least mean square line fitted through the data gives a measure of the fraction of the element in the coal that is vaporized and recondensed.

\section{Arsenic:}

The results are all fitted by the same line with modest scatter (Figure 3-14). The fractional vaporization is 0.4 . The points that depart significantly from the correlation are the low rank coals (MS, MR, WY) in the Quann et al. ${ }^{1}$ study. In these coals there is opportunity for the vaporized arsenic to react with calcium oxide in the residual fly ash, thus reducing the amount that condenses in the submicron aerosol. This hypothesis will be tested when the low rank coal in the present study is burned.

\section{Zinc:}

The data in the Quann et al. ${ }^{1}$ study (Figure 3-15) were correlated with two lines (fractional vaporizations of 0.06 and 0.26 ), one for the low rank and the other for the high rank coals. The data in the present study show the interesting anomaly that the result for the Elkhorn/Hazard coal (KY) are more consistent with the low rank coals in the Quann et al. ${ }^{1}$ data than the bituminous coal. There is also an interesting size dependence of the vaporization of the zinc in the dense fraction of the Illinois coal. 


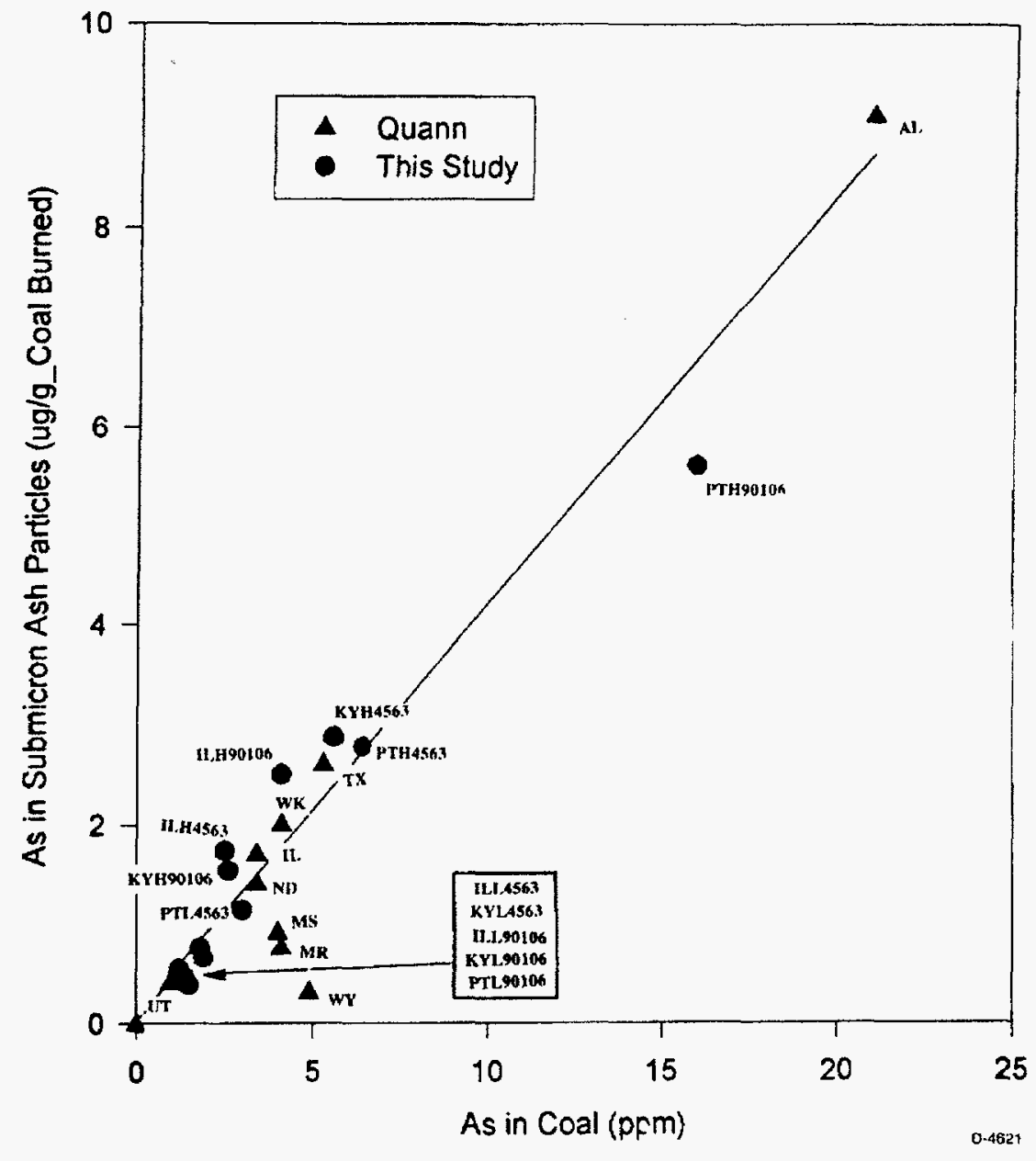

Figure 3-14. Effect of As concentration in coal on the total As collected in submicron ash.

\section{Iron:}

The data for iron (Figure 3-16) show a much smaller vaporization than arsenic and zinc, with a fractional vaporization of 0.027 . The points lying above the line are the low rank coals from the Quann et al. ${ }^{1}$ study and the Elkhorn/Hazard (KY) coal from the present study. Again, the Elkhorn/Hazard coal shows a resembling that of a low rank instead of a high rank coal.

\section{Chromium:}

The data show considerable scatter (Figure 3-17). Insights on the cause for this scatter may be obtained from the major differences seen with changing density for the $45 / 63 \mu \mathrm{m}$ fractions for the Illinois No. 6 (IL), Pittsburgh (PT), and Elkhorn/Hazard (KY) coals. 


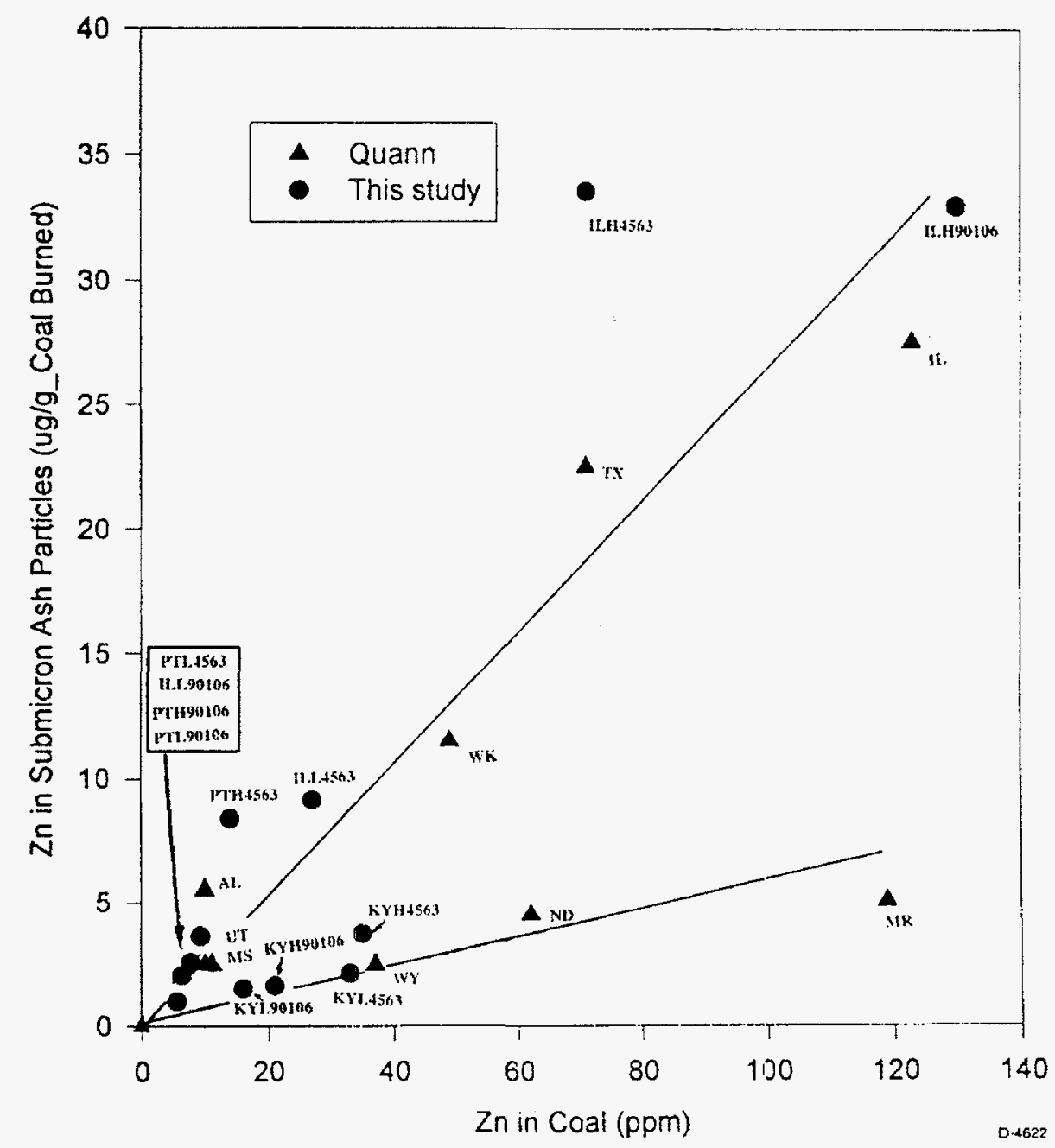

Figure 3-15. Effect of $\mathrm{Zn}$ concentration in coal on the total Zn collected in submicron ash.

\section{Sodium:}

For the present coal, the Pittsburgh and the Elkhorn/Hazard coals show lower vaporization than the Illinois No. 6 (Figure 3-18). There is also considerable scatter in the results of Quann et al. ${ }^{1}$ which may be caused by the same inter-coal differences. One possible explanation for these differences may be difference in the extent of reaction between sodium and silica in the different coals. If this were the case, then the vaporization of the sodium for the lower rank coals should be higher than those for the higher rank coals. This seemss to be the case. Knowledge of the size of the silica mineral inclusions is needed to be able to assess these effects. CCSEM data will be obtained for that purpose. 


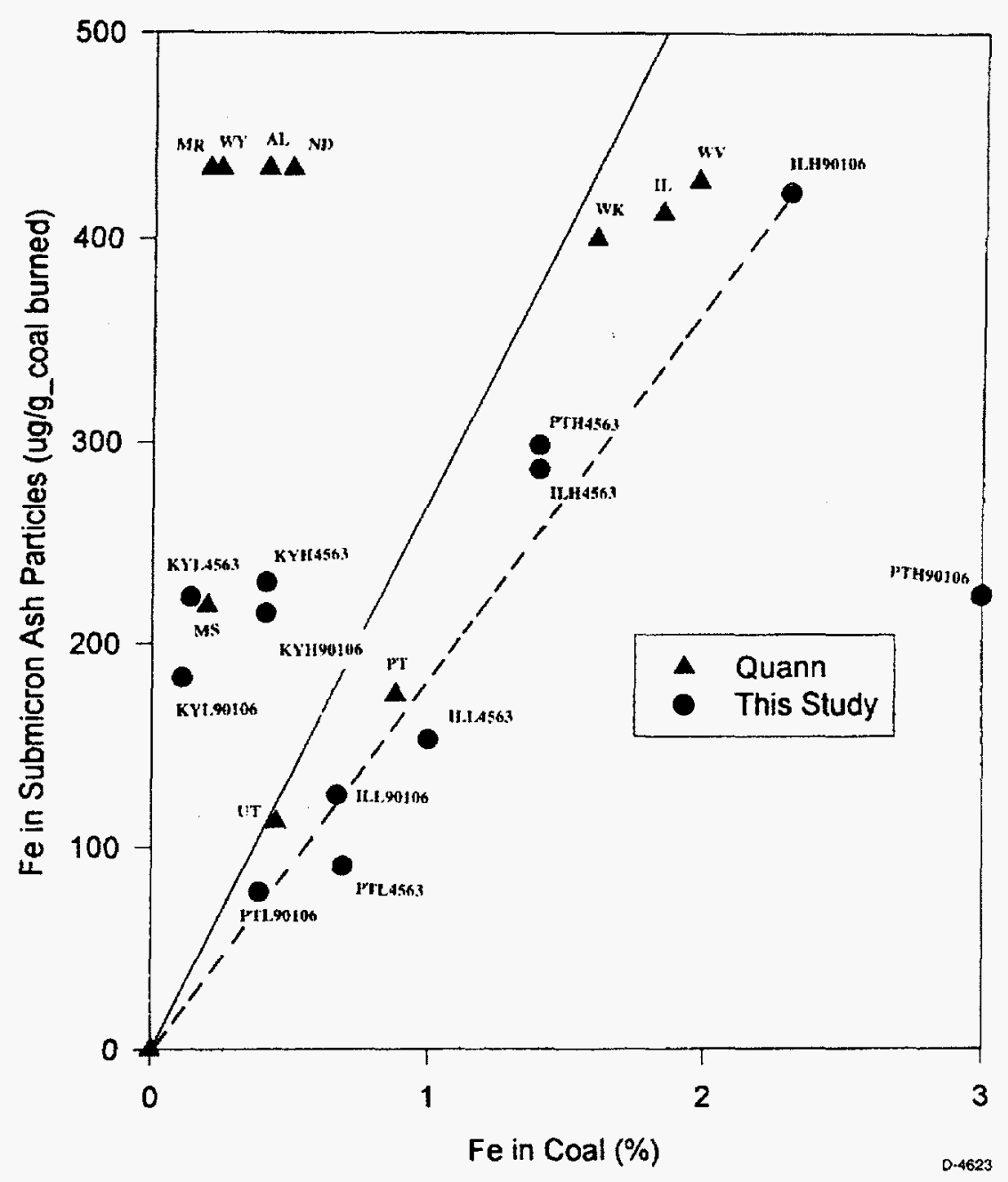

Figure 3-16. Effect of Fe concentration in coal on the total Fe collected in submicron ash.

\section{Mercury:}

The results on mercury are of interest in that they show high values of mercury capture by the ash, particularly for the Pittsbugh coal (Table 3-4). The mercury is captured primarily with the large, residual ash. It is probable that the mercury is captured with carbon, either char or soot, in the ash. The amount of carbon is relatively small based on measurement of weights of the residual ash which did not reveal the carbon within the uncertainty in the mass balance.

The results from this study will be used to guide the mineral characterization studies. For arsenic, the interest is in the size of calcium-rich inclusions in the coal. For sodium, it is the size of the silica inclusions. For mercury, separate runs will need to be made for purposes of obtaining carbon content. As more elements are analyzed, additional leads are expected to emerge. 


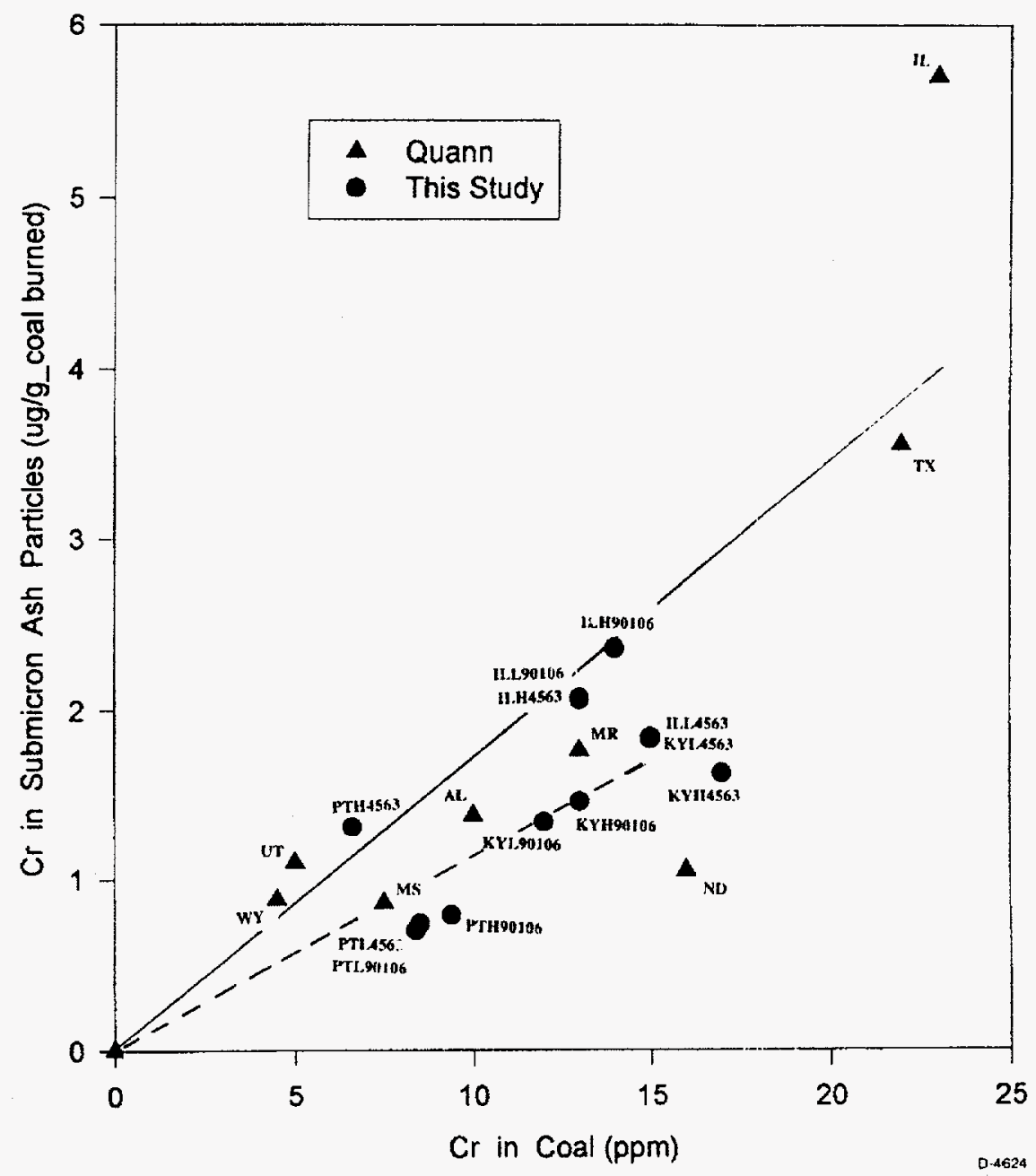

Figure 3-17. Effect of $\mathrm{Cr}$ concentration in coal on the total $\mathrm{Cr}$ collected in submicron ash.

Table 3-4. Hg Distribution in Ash Produced by Coal Combustion at $\mathrm{T}_{\text {furnace }}=1700 \mathrm{~K}, \mathrm{O}_{2}=20 \%$

\begin{tabular}{|l|c|c|}
\hline & $\begin{array}{c}\text { Percentage in Larger Ash } \\
\text { Particale (>1 micron) } \\
(\%)\end{array}$ & $\begin{array}{c}\text { Percentage in } \\
\text { Submicron Ash Particle } \\
(\%)\end{array}$ \\
\hline \hline KY H 4563 & 36 & 2.5 \\
KY L 4563 & 29 & 8.5 \\
KY H 90106 & 86 & 0.2 \\
KY L 90106 & 84 & 6 \\
\hline PT H 4563 & 61 & 2.4 \\
PT L 4563 & 95.6 & 4.4 \\
PT H 90106 & 19 & 0.3 \\
PT L 90106 & 94 & 6 \\
\hline IL H 4563 & 16 & 1.7 \\
IL 4 4563 & 18 & 14.6 \\
IL H 90106 & 13 & 0.7 \\
IL 90106 & 21 & 3 \\
\hline
\end{tabular}




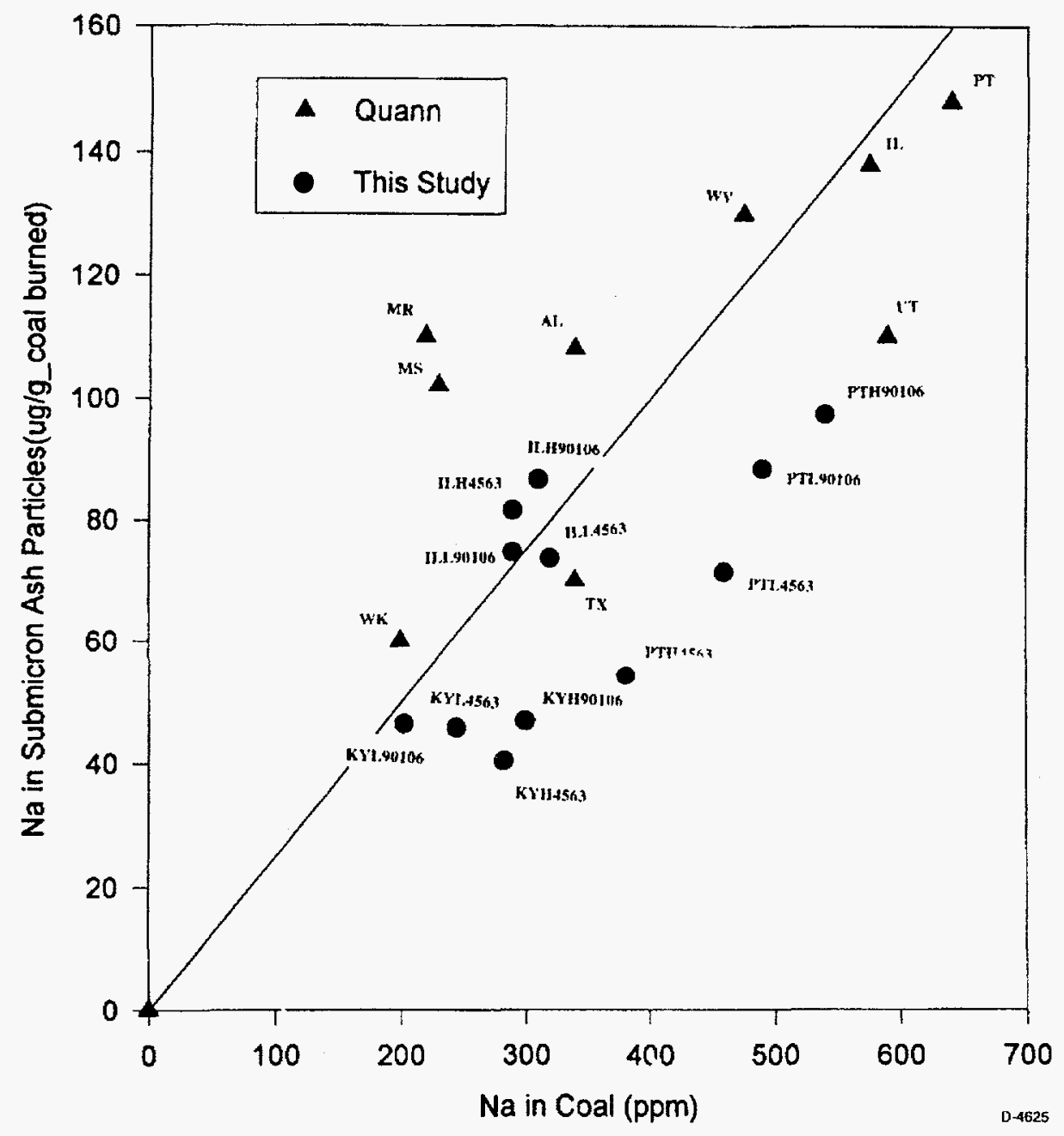

Figure 3-18. Effect of $\mathrm{Na}$ concentration in coal on the total Na collected in submicron ash.

\subsection{Post-Combustion Transformations (UA, PSI, UKy)}

Trace element transformations in the region between the furnace exit and the ESP play a critical role in determining the partitioning of that element between flyash captured in the ESP and vapors emitted from the stack. In this program we are investigating these post-combustion transformations on two different scales. Mercury capture by residual carbon, shown to be an important mechanism for mercury retention in the ash, is being evaluated in a small benchtop facility. Interactions, such as condensation and reactive scavenging, between vaporized species such as arsenic and selenium are being investigated using the larger self-sustained combustor at UA. Mercury speciation in flue gas is being evaluated in the PSIEFR.

\subsubsection{Mercury Capture by Residual Carbon}

During the last quarter the PSI EFR was used to produce partially combusted chars from three of the program coals. The Elkhorn/Hazard, the Pittsburgh, and the Illinois No. 6 coals were 
all combusted at a stoichiometric ratio of 0.6 , and a maximum gas temperature of $1450^{\circ} \mathrm{C}$. The resulting chars were then sent to the UA for the mercury capture experiments. Because the presence of sulfur in activated carbon has been shown to affect mercury uptake, a small sample of the chars were sent to the UKy for XAFS analysis, and to a commercial laboratory for forms of sulfur analysis. The data from the commercial laboratory will be discussed in the next quarterly report.

Figure 3-19 shows the sulfur XANES spectra of char samples prepared from the project coals. These spectra are $: 2$ the process of being analyzed according to least-squares fitting procedure developed for sulfur in coals and chars and only a preliminary semi-quantitative analysis will be presented here. Approximate estimates of the $\% \mathrm{~S}$ in different forms in the three chars are given in Table 3-5.

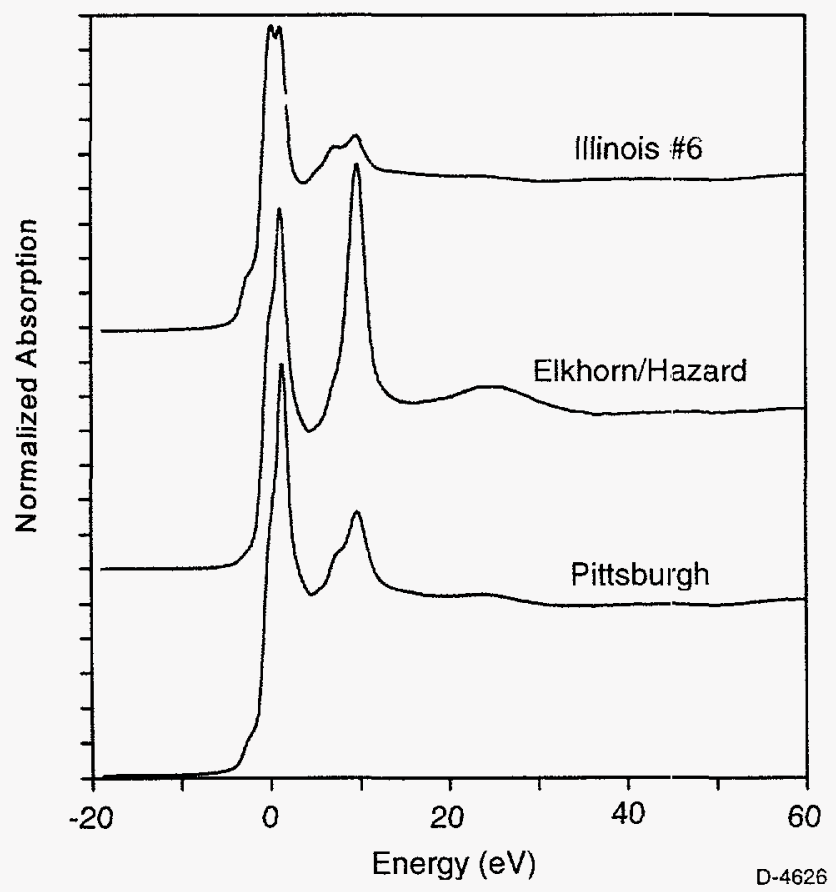

Figure 3-19. Sulfur XANES spectra of chars from three program coals.

Table 3-5. \%S in Different Forms in Char Samples from Sulfur XANES Spectroscopy

\begin{tabular}{|l|c|c|c|c|c|c|}
\hline \multirow{2}{*}{ Sulfur Form } & \multicolumn{2}{|c|}{ Elkhorn/Hazard } & \multicolumn{2}{c|}{ Pittsburgh } & \multicolumn{2}{c|}{ Illinois \#6 } \\
\cline { 2 - 7 } & $\mathrm{P}$ in eV & $\% \mathrm{~S}$ & $\mathrm{P}$ in eV & $\% \mathrm{~S}$ & $\mathrm{P}$ in eV & $\% \mathrm{~S}$ \\
\hline \hline Pyrrhotite & -- & $<5$ & -2.2 & 20 & -2.2 & 35 \\
\hline Elemental Sulfur & 0.1 & 30 & 0.0 & 25 & 0.1 & 35 \\
\hline Organic Sulfide & 1.5 & 42 & 1.5 & 50 & 1.5 & 29 \\
\hline Sulfate & 10.1 & 25 & 9.9 & 5 & 9.8 & 2 \\
\hline Other & -- & $<3$ & -- & -- & -- & - \\
\hline
\end{tabular}


The prominent shoulder at about $-2.2 \mathrm{eV}$ in the Pittsburgh and Illinois \#6 samples is due to pyrrhotite, whereas the second shoulder at about $0.0 \mathrm{eV}$ in Elkhorn/Hazard and Pittsburgh coals and the peak at $0.0 \mathrm{eV}$ in Illinois \#6 coal is due to elemental sulfur. The sulfate peak at around $10 \mathrm{eV}$ for the Elkhorn/Hazard coal is much larger than those for the Ilinois and Pittsburgh coals. The spectra indicate that pyrite in the coal has decomposed to a mixture of pyrrhotite $\left(\mathrm{Fe}_{1-\mathrm{x}} \mathrm{S}\right)$ and elemental sulfur. Interestingly, the $\% \mathrm{~S}$ in the form of pyrrhotite and elemental sulfur are approximately the same for the Illinois \#6 and Pittsburgh coals, whereas the elemental sulfur is much higher than the pyrrhotitic sulfur for the Elkhorn/Hazard coal. However, it should be noted that the $\% S$ as sulfate is almost the same as the $\% \mathrm{~S}$ as elemental sulfur for this coal, suggesting, perhaps, that the lack of observation of pyrrhotite is because the pyrite or the pyrrhotite has oxidized to sulfate, either during or prior to the char formation from the Elkhorn/Hazard coal. Whether this difference reflects the lower iron content of this coal or the fact that the Elkhorn/Hazard coal is more highly oxidized than the other two coals has yet to be resolved. Also, it should be recalled that sulfur can also escape from the coal during char formation and, therefore, a more detailed analysis must await a determination of total sulfur in these char samples.

While the chars were being prepared and characterized, work continued on the experimental apparatus and procedure for the mercury capture experiments. A schematic diagram of the experimental apparatus is given in Figure 3-20. The gas preparation section consists of gas sources (1) and a water saturator (2). This section is designed to deliver a simulated flue gas with a composition of $80 \%$ nitrogen, $15 \%$ carbon dioxide, $3 \%$ water vapor, and $2 \%$ oxygen. The gas flow rates are measured and monitored by three mass flow controllers to control the nitrogen,

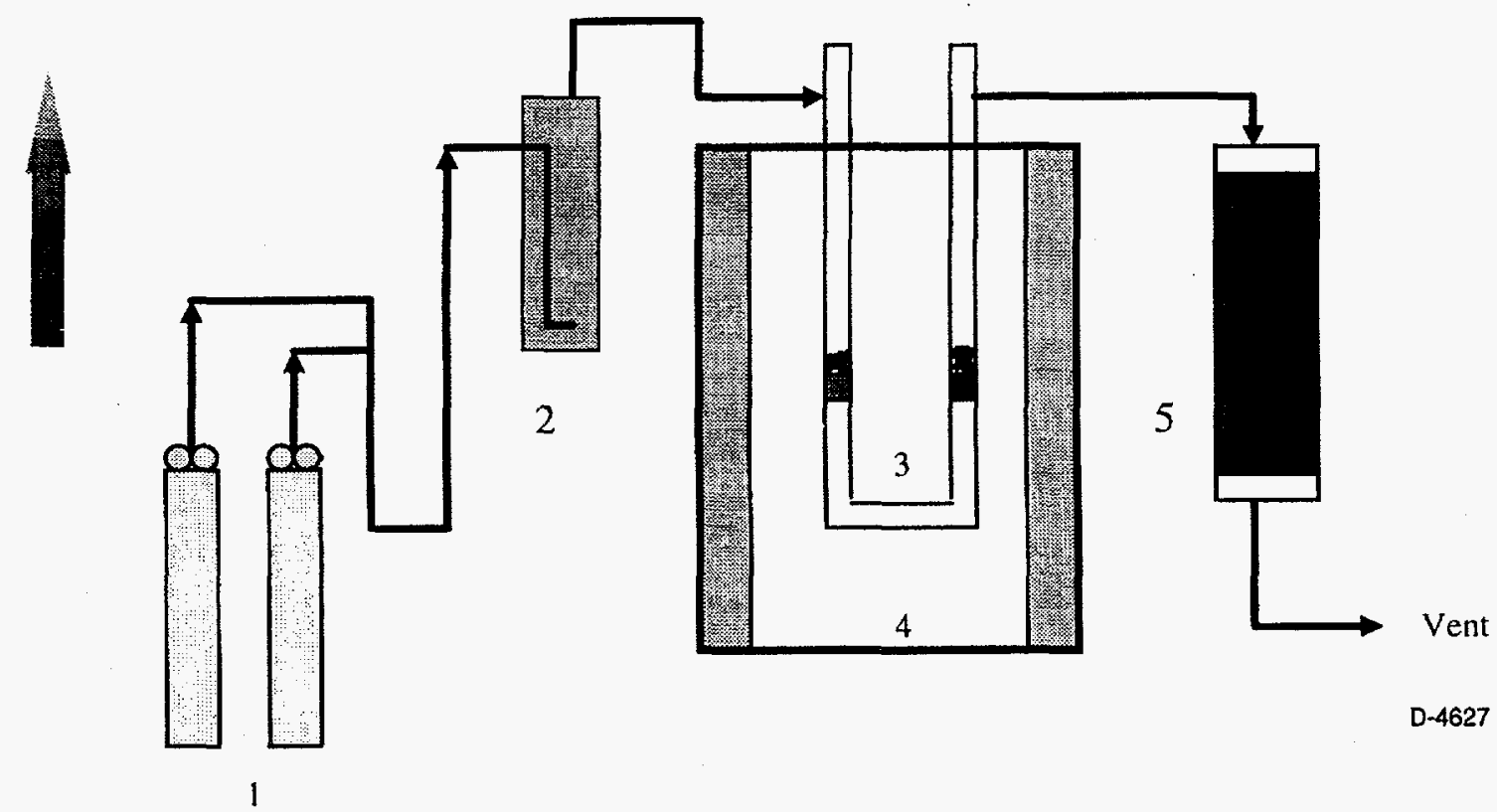

Figure 3-20. Schematic of reactor for mercury capture experiments; (1) gasses, (2) water saturator, (3) reactor, (4) constant temperature controller. 
carbon dioxide, and air. These flow controllers are calibrated with standard calibration gases. The reactor section consists of a reactor (3) and a heating source whose temperature is controlled by a constant temperature controller (4). The reactor is a U-shaped tube. Mercury is placed into the left side of the U-shaped reactor and the mercury vapor generated is brought by the simulated flue gas into the right side of the reactor where the sorbent is placed. The required reactor temperatures are obtained by placing them into well controlled heat sources. The temperature of the mercury source and the temperature of the sorbent can be controlled independently. The last section consists of two activated carbon columns placed in series to ensure complete removal of mercury before venting to the atmosphere for the safety and environmental concerns.

During the experiments the desired temperature are achieved by setting and adjusting the constant temperature controllers. Both temperatures are held constant during the period of experiment. Once the temperatures are constant, the simulated flow gas (SFG) is introduced by the gas preparation section. The mercury source is then placed into an glass basket, which is then put into the source reactor. The mercury is vaporized inside the source reactor and the vaporized mercury is then carried away by the SFG into to the sorbent reactor. The sorbent to be tested (partially combusted char) is placed in the sorbent reactor on an distribution bed. The sorption begins when the mercury containing SFG flow through the reactor. The SFG then flows through the carbon traps to remove the remaining mercury vapor before the gas is exhausted to the atmosphere.

The concentration of mercury in the gas phase is extremely important, and will be calibrated by two methods. One is the direct weighting method. The weights of the mercury source before and after each experiment are measured by a analytical balance up to four digital accuracy. The gas concentration is then calculated by using the weight difference and the gas flow rate. The second method is using atomic adsorption. This is done by a blank run with only source in the source reactor while keeping the other conditions the same with experimental conditions. The vaporized mercury is then condensed or captured totally by a downstream device. The captured mercury is then analyzed by atomic adsorption to determine the mercury concentration. The concentration of mercury in the reactant is determined by cold vapor atomic adsorption spectroscopy. The data are used to determine the sorption ability and capacity of sorbent.

The planned experimental conditions are as follows:

$\begin{array}{ll}\text { Mercury source temperature: } & 70^{\circ} \mathrm{C} \\ \text { Sorbent reaction temperature: } & 70 \text { and } 160^{\circ} \mathrm{C} \\ \text { Flow rate: } & 100 \mathrm{scc} / \mathrm{min} \\ \text { Gas composition: } & \mathrm{SFG}\end{array}$

\subsubsection{Forms of Mercury Captured by Residual Carbon}

Given the importance of residual carbon on mercury retention in fly ash, it is important to get a better understanding of the forms of mercury present in the char. Through an arrangement between the DOE Project Manager of closely allied DOE research projects (T. Brown) and the Principal Investigators on these programs, char and ash samples were received from Radian 
International and from the Energy and Environmental Research Center at the University of North Dakota (UNDEFRC) that had been exposed to a simulated flue gas containing elemental mercury. The objective was to identify the forms of mercury and other significant elements in these chars using XAFS spectroscopy.

Samples of char and ash from both Radian and UNDEERC were run at the $\mathrm{Hg} \mathrm{L}_{\mathrm{III}}$ edge at $12,284 \mathrm{eV}$ at SSRL during November 1996. Some preliminary data are presented here for mercury in four activated carbon samples from UNDEERC as these samples had by far the highest levels of mercury in them. Furthermore, as we could not detect a useful edge in any other sample, we conclude that the mercury contents were less than $2 \mathrm{ppm}$ in all other samples.

The four samples consist of two composite activated carbons prepared from lignite (LAC-1, LAC-2), a sulfur-impregnated activated carbon (SAC-1), and an iodine-impregnated activated carbon (IAC-1). All four samples had been exposed to the simulated flue gas doped with elemental mercury. Corresponding blank samples (LAC-3, SAC-2, and IAC-2) that had not been exposed to the gas were also supplied.

The mercury XANES spectra for the four carbon samples are shown in Figure 3-21. As with the all mercury XANES spectra, the fine structure is rather subtle and we have resorted to using the first differential of the spectrum to quantify differences among the spectra. As can be seen from the figure, the fine structure becomes more prominent in the order IAC- $1<\mathrm{LAC}-1$, LAC- $2<$ SAC-1 and is accompanied by an increasing separation of the two peaks in the first differential spectra. Based on work on other mercury standards, it would appear that the separation of the peaks is highest for ionic mercury compounds and least for covalent and metallic mercury compounds. The observed trend for the peak separation in the activated

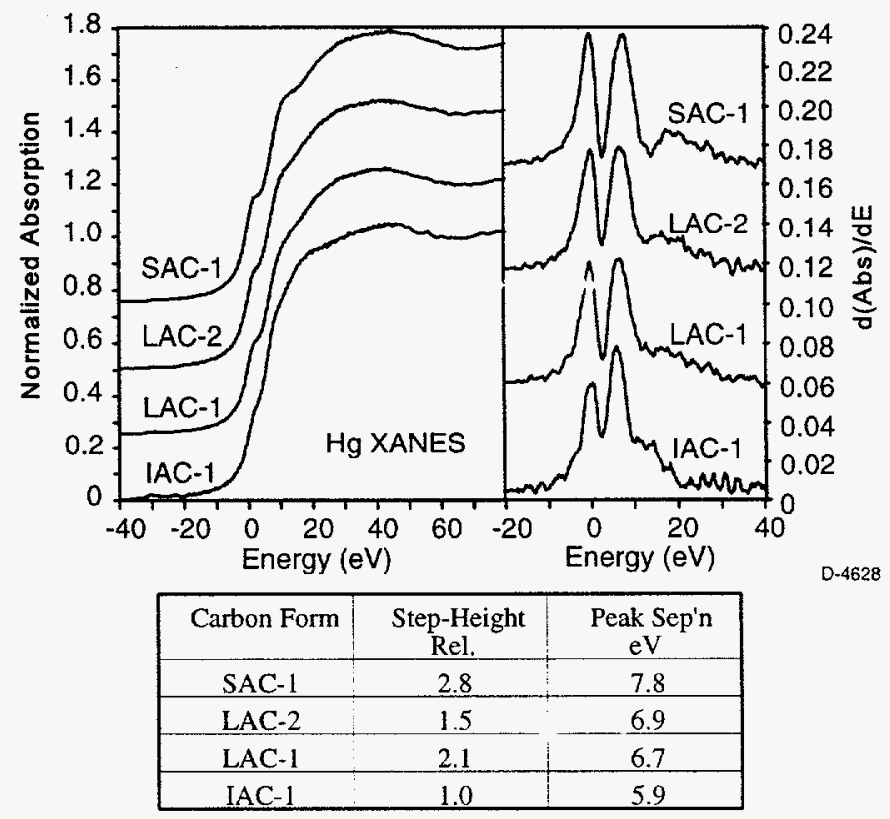

Figure 3-21. Hg XANES spectra and related data for four chars supplied by UNDEERC. 
carbons would be consistent with $\mathrm{Hg}$-S bonding in the SAC char and $\mathrm{Hg}$-I bonding in the IAC char. Further evidence for this trend can be seen from an analysis of the EXAFS regions of the XAFS spectra presented in Figure 3-22. The radial structure functions (RSFs) shown in Figure 3-22 indicate a significantly different structure for $\mathrm{Hg}$ in the iodine-impregnated carbon. In particular, the $\mathrm{Hg}-\mathrm{X}$ bond for IAC-1 is much longer than those indicated for $\mathrm{Hg}$ in SAC-1 and for LAC-1,2. The bond distance for $\mathrm{Hg}-\mathrm{I}$ in $\mathrm{HgI}_{2}$ is about $2.78 \AA$, whereas the $\mathrm{Hg}$-S bond distance in cinnabar ( $\mathrm{HgS}$ ) is about $2.36 \AA$, the $\mathrm{Hg}$-Cl bond distance in $\mathrm{HgCl}_{2}$ is about $2.25 \AA$, and the $\mathrm{Hg}-\mathrm{O}$ bond distance in $\mathrm{HgO}$ is about $2.03 \AA$. Further work is planned to compare the RSFs obtained for the activated carbons with those obtained from mercury standard compounds of known structure.

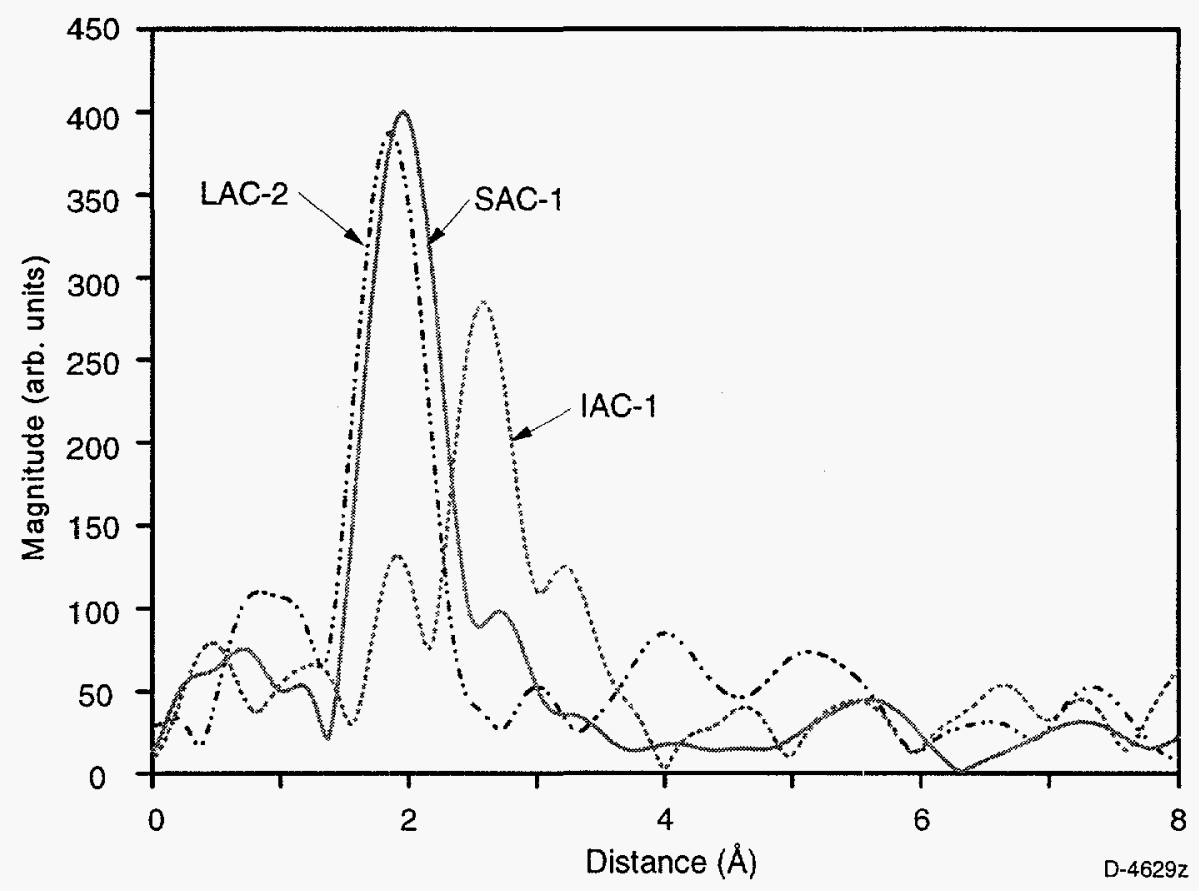

Figure 3-22. Radial structure functions for $\mathrm{Hg}$ in three activated carbons.

In addition to data on mercury, XAFS data will also be obtained at the sulfur, calcium, iodine, and possibly other element absorption edges. This will be done in the next XAFS session starting January 27 th.

\subsubsection{Mercury Speciation Measurements}

The oxidation state of mercury plays a critical role in its ability to be controlled by air pollution control devices. For example, oxidized mercury is more readily removed in a wet scrubber than elemental mercury. This important fact led to a great deal of work on the measurement of speciation of mercury in flue gas. Equilibrium calculations suggest that mercury is entirely in the elemental form at the high temperatures associated with the combustion zone. As the gas cools equilibrium predicts that the mercury oxidizes. However, as discussed in Quarterly Report No. $4^{2}$ some field data suggests that the mercury oxidation is 'frozen' at some 
temperature around $850 \mathrm{~K}$. To test whether oxidation is indeed frozen at some temperature, a series of experiments are underway to measure the mercury speciation in real flue gas at a range of temperatures.

For these experiments the Illinois No. 6 coal was combusted under fuel lean conditions (stoichiometric ratio of 1.2). Flue gas was removed at the bottom of the reactor and immediately quenched with nitrogen. As the water-cooled nitrogen quench probe was not used for these experiments, the temperature of the gas at the quench location was that at the furnace exit. This temperature, $<754 \mathrm{~K}$, is measured as part of the experimental protocol. The preliminary mercury speciation measurements utilized the Ontario-Hydro method. This method was identified by a FETC-EPRI-UNDEERC team as one of the more reliable methods for measuring mercury speciation in flue gas.

The apparatus for the Ontario-Hydro method is shown schematically in Figure 3-23. The gas sampling apparatus for this method consisted of a glass cyclone followed by a $100 \mathrm{~mm}$ diameter polycarbonate particulate filter, then a series of nine $500 \mathrm{ml}$ modified Greenburg-Smith impingers through which the quenched flue gas flowed. The cyclone served to remove the larger particles in the gas stream to minimize contact with the vaporized mercury. Each impinger contained $100 \mathrm{ml}$ of solution as follows: the first three impingers contained $1 \mathrm{M} \mathrm{KCl}$, impingers four and five contained a $10 \% \mathrm{H}_{2} \mathrm{O}_{2} / 5 \% \mathrm{HNO}_{3}$ solution and six through eight contained $4 \% \mathrm{KMnO}_{4}$ in $10 \% \mathrm{H}_{2} \mathrm{SO}_{4}$. The final impinger contained 6 to 16 mesh indicating silica gel. The sampling time was $2 \mathrm{~h}$ and was calculated to collect well above the minimum mercury detection limit using the expected mercury concentration in the gas flows used.

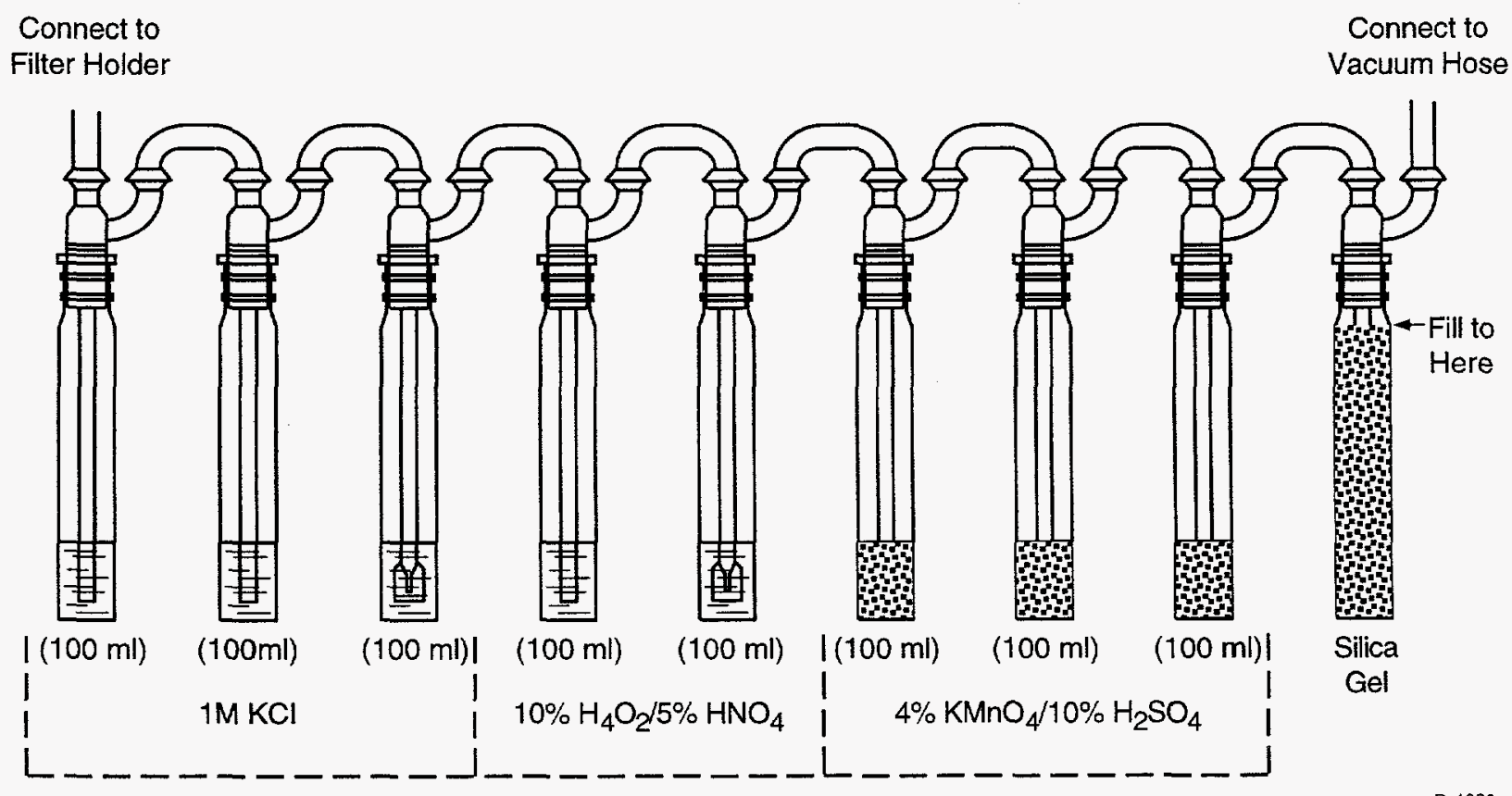

Figure 3-23. Schematic of the Ontario-Hydro apparatus. 
The first step in sample recovery at the end of the run involved collecting and weighing particulate from the cyclone, filter and connecting glassware. The particulate was placed in Container \#1. Then the glassware was rinsed with 0.1 nitric acid and this rinse added to the contents of the $\mathrm{KCl}$ impingers in Container \#2. Container \#3 held the contents and rinses of the peroxide/nitric acid impingers. The contents of the potassium permanganate impingers were placed in Container \#4 then each of these impingers was rinsed with 0.1 nitric acid, $8 \mathrm{~N} \mathrm{HCl}$ and 0.1 nitric acid again and the rinse added to Container \#4. The particulate in Container \#1 was then prepared by acid microwave digestion using $\mathrm{HF}, \mathrm{HCl}$ and $\mathrm{HNO}_{3}$ acids then analyzed for $\mathrm{Hg}$ by CVAAS. Sample preparation for Container \#2 consisted of cligesting a small sample with $\mathrm{H}_{2} \mathrm{SO}_{4}, \mathrm{KMnO}_{4}$, and $\mathrm{K}_{2} \mathrm{~S}_{2} \mathrm{O}_{8}$, heating for $2 \mathrm{~h}$ at $95^{\circ} \mathrm{C}$, then reducing with hydroxylamine sulfate. For Container \#3, the procedure was to digest with concentrated $\mathrm{HCl}$, then add $\mathrm{KMnO}_{4}$ until the solution remained brownish-purple. It was then reduced with hydroxylamine sulfate. The contents of Container \#4 were prepared by adding hydroxylamine sulfate until colorless, then all three solutions were analyzed by CVAAS.

These data from analysis of the various solutions and the ash indicated that approximately $16 \%$ of the mercury was retained in the ash at these temperatures. The vapor phase mercury was approximately $72 \%$ elemental mercury and $28 \%$ oxidized mercury. Mass closure for this experiment was approximately $100 \%$. Equilibrium predictions for this coal suggest that these two values should be reversed. The temperature where the equilibrium mercury speciation corresponds to the measured speciation is approximately $850 \mathrm{~K}$. These results tend to corroborate the 'frozen equilibrium' hypothesis discussed in the last quarterly. More measurements are required to confirm these results.

\subsubsection{Large Scale Combustion Experiments}

During December a joint team of PSI and UA investigators performed a series of experiments designed to measure trace element partitioning in the self-sustained laboratory scale combustor. The experimental plan was to collect and size segregate fly ash samples using a water-cooled quench probe and the Berner Low Pressure Impactor (BLPI). Samples were to be collected at the top of the furnace, immediately after char burnout is complete, and at the furnace exit where the gas temperature had cooled to approximately 600 to $800^{\circ} \mathrm{C}$. By sampling at these two locations it will be possible to explore how the trace element partitioning changes from the flame zone (at the top of the furnace) to the exit.

Several equipment malfunctions prevented completion of the experimental plan. During the first experiment the cooling water jacket of the installed burner developed a serious leak into the furnace -- quenching the flame. A spare burner of a different design was then installed. This spare burner had been used on several prior coal combustion programs on this facility. By utilizing this burner it was possible to test the entire system for an extended period of time. These tests did not yield viable ash samples, but did show that all systems of the UA self-sustained downflow combustor are now ready for final experimentation, and that the combustor/baghouse and sampling and analytical systems can be operated for extended periods without major problems, other than slag build-up. The BLPI was left at UA to be used in the upcoming sampling runs. These sampling runs are underway and will be discussed in the next quarterly report. 
SECTION 4

CONCLUSIONS

4-1/4-2 


\section{CONCLUSIONS}

The data obtained during the last quarter and described above has helped to further our understanding of trace element forms of occurrence in coal and how these forms of occurrence may affect trace element vaporization. XAFS analysis of the Illinois No. 6 and Elkhorn/Hazard coal indicate that the forms of selenium present differ dramatically between these coals. In the Ilinois No. 6 the selenium is predominantly associated with pyrite. In fact, there is a good correlation between the distribution of arsenic, shown to be associated with pyrite in this coal, between the various density fractions and the selenium distribution. For the Elkhorn/Hazard coal the primary form of selenium is as organoselenium.

Arsenic leaching data were also used to draw preliminary conclusions about the forms of occurrence and mineral association of this element in the three bituminous coals. In both the Illinois No. 6 and Pittsburgh coals the arsenic was primarily removed with the nitric acid. This result suggests that arsenic is associated with pyrite, a finding which is in agreement with the XAFS data presented in earlier reports. For the Elkhorn/Hazard coal a substantial portion of the arsenic was not leached by any of the solvents. One possible explanation for this finding is that the arsenic is associated with finely divided pyrite inclusions which may be shielded from the leaching solution by the carbon. Work is underway to test this explanation.

Combustion testing during the last quarter has demonstrated that trace element vaporization is strongly dependent on both the concentration of a given element in coal and the combustion environment. Vaporization data from the MIT droptube was compared with data from Quann et al. ${ }^{1}$ Vaporization was found to increase linearly with trace element concentration for a wide range of coals. The fractional vaporization (the slope of the line) varied from element to element, and in some cases, from coal type to coal type. Vaporization data from the PSI EFR indicated that the fractional vaporization of 'volatile' elements such as arsenic, selenium, and antimony, depends strongly on the oxygen concentration present during char burnout. Combustion under fuel lean conditions lead to much higher vaporization than combustion under fuel rich conditions. The reason for this increased vaporization under fuel lean conditions may include higher particle temperatures, and slower oxidation rates of minerals such as pyrite.

Mercury capture and speciation was also addressed in a preliminary fashion in the last quarter. Mercury speciation experiments on the PSI EFR suggested that the fractional oxidation at temperatures less than $750 \mathrm{~K}$ was much lower than would be predicted by equilibrium. In fact, the measured value was consistent with equilibrium being 'frozen' at a temperature of approximately $850 \mathrm{~K}$. This finding supports the earlier hypothesis that oxidation of mercury is frozen at some temperature around $850 \mathrm{~K}$. Additional work continues to both validate this hypothesis and to measure mercury capture by coal chars. 
SECTION 5

REFERENCES 



\section{REFERENCES}

1. Quann, R.J., Neville, M., Sarofim, A.F., "A laboratory study of the effect of coal selection on the amount and composition of combustion generated submicron particles," Comb. Sci. and Tech. 74, 245-265 (1990).

2. Bool, III, L.E., Senior, C.L., Huggins,F., Huffman, G.P., Shah, N., Wendt, J.O.L., Sarofim, A., Olmez, I., and Zeng, T., "Toxic Substances from Coal Combustion -- A Comprehensive Assessment," Quarterly Report No. 4 prepared for Department of Energy, PETC, under Contract No. DE-AC22-95PC95101, PSIT-1245, October (1996).

3. Palmer, C.A., Krasnow, M.R., Finkelman, R.B., and D'Angelo, W.M., "An evaluation of leaching to determine modes of occurrence of selected toxic elements in coal," Journal of Coal Quality 12 (4), 135-141 (1993).

4. Finkelman, R.B. Palmer, C.A., Krasnow, M.R., Aruscavage, P.J. Sellers, G.A., and Dulong, F.T., 1990, "Combustion and leaching behavior of elements in Argonne Premium Coal Samples," Energy and Fuels 4(5), 755-766, (1990).

5. Bool, III, L.E., Senior, C.L., Huggins,F., Huffman, G.P., Shah, N., Wendt, J.O.L., Sarofim, A., Olmez, I., and Zeng, T., "Toxic Substances from Coal Combustion -- A Comprehensive Assessment," Quarterly Report No. 1 prepared for Department of Energy, PETC, under Contract No. DE-AC22-95PC95101, PSIT-1245, January (1995). 


\begin{abstract}
APPENDIX A
PRELIMINARY RAW LEACHING DATA -DERIVED FROM ANALYSIS OF LEACHATE SOLUTIONS
\end{abstract}

